\title{
SÖZLÜ KÜLTÜRDE KADININ TEMSILII VE YENİ MEDYADA KADIN FENOMENLERİN GÖRÜNÜMLERİ: ELEŞTİREL SOSYOLOJIK BİR BAKIŞ
}

\section{Özlem AYDOĞMUŞ ÖRDEM ${ }^{1}$}

\section{ÖZET}

Kadın çalışmaları özellikle İkinci Dünya Savaşı’ndan sonra artmış ve bu çalışmalar modernite paradigmasında baskın olan üst anlatılara karşı birçok eleştirel bakış geliştirmiştir. Kadınların nasıl temsil edildiği ve kendilerini nasıl temsil ettikleri tarihsel ve eşsüremli bir süreklilik içerisinde ele alınması gerekmektedir. Sözlü kültürden günümüz yeni medya kültürüne kadar erkek egemen kültürün hakim olmasından dolayı kadınlar sosyo-politik alanın dışında bırakılmış ve popüler kültürün temsili haline getirilmiştir. Bu çalışmada sözlü kültürde yer alan kadınların tarihsel temsili ile yeni medyadaki kadınların kendilerini nasıl temsil ettiği sosyo-politik açıdan eleştirel bir sosyolojik bakış açısı ile ele alınmıştır. Çalışmada sözlü kültürde temsil edilen 10 kadın ile yeni medyada instagram fenomeni olan 10 kadının temsil özellikleri incelenmiştir. Çalışmanın verileri nitel desende tematik olarak tümevarımsal içerik analizi ile yorumlanmıştır. Çalışmanın sonuçları, kadının sözlü kültürde sosyopolitik olarak bastırıldığını ve aynı zamanda doğurganlık, güzellik, çekicilik ve duygusal özellikleri ile temsil edildiğini göstermektedir. Yeni medyada ise kadının sosyo-politik konuları paylaşmadığı ve güzellik, çekicilik, seyahat, zekâ, moda ve sosyal sorumluluk gibi riskli olmayan konularda ön plana çıktı̆ı̆ görülmektedir. Çalışma, yeni medyadaki kadınların genel olarak eşitsizlik, adaletsizlik, ayrımcılık ve kadına şiddet gibi sosyo-politik konularda paylaşımlarda bulunmadığını göstermektedir. Kadınların yeni medya aracılı̆̆ı ile özcü kategorilere dayanmayan postyapısalcı paradigma çerçevesinde sosyo-politik konuları tartışarak, toplumu dönüştürmede önemli etkilerinin olacağı düşünülmektedir.

Anahtar Sözcükler: Kadın, Sözlü Kültür, Yeni Medya, Postyapısalclık, Popüler Kültür, Sosyo-Politik Konular

${ }^{1}$ Doç. Dr., Çukurova Üniversitesi, İletişim Fakültesi İletişim Bilimleri Bölümü 


\title{
REPRESENTATION OF WOMEN IN ORAL CULTURES AND VISIBILITY OF WOMEN INFLUENCERS IN NEW MEDIA: A CRITICAL SOCIOLOGICAL PERSPECTIVE
}

\begin{abstract}
Women's studies have increased especially after the Second World War and these studies have developed many critical perspectives against the meta-narratives dominant in the modernity paradigm. How women are represented and how they represent themselves needs to be addressed on a historical and synchronous continuum. Due to the dominance of male-dominated culture from oral culture to today's new media culture, women have been excluded from the socio-political sphere and made representation of popular culture. In this study, the historical representation of women in oral culture and how women in the new media represent themselves are discussed from a socio-politically critical point of view. In the study, 10 women represented in oral culture and 10 women, Instagram influencers in new media were examined. The data of the study were interpreted thematically in qualitative design using inductive content analysis. The results of the study show that the women are socio-politically suppressed in oral culture and at the same time represented by her fertility, beauty, charm, and emotional qualities. In the new media, it is seen that women do not share socio-political issues and come to the fore with non-risky issues such as beauty, charm, travel, intelligence, fashion and social responsibility. The study shows that women in the new media generally do not post on socio-political issues such as inequality, injustice, discrimination and violence against women. It is thought that women will have important effects in transforming the society by discussing socio-political issues within the framework of the poststructuralist paradigm that does not rely on essentialist categories through new media.
\end{abstract}

Keywords: Women, Oral Culture, New Media, Popular Culture, Poststructuralism, Socio-Political Problems 


\section{Gİiș}

Kadının sözlü, yazılı ve görsel medyadaki temsili ve görünürlüğü tarihsel bir süreklilik içeren kodlardan oluşmaktadır. Bu çalışma sözlü kültür ile yeni medya sürecinde kadınların temsili bakımından bir sürekliliğin olduğunu ve bir ilişkinin kurulabileceğini göstermeyi hedeflemektedir. Mitoloji ve sözlü kültürde temsil edilen kadınlar ile yeni medyada kendini temsil eden kadınlar arasında erkek egemenliğini gösteren ve kadının bedenselliğine, uyumsuzluğuna, duygusal yönlerine gönderme yapan özellikler bakımından bir ilgileşim olduğu söylenebilir. Tarih boyunca erkeklerin egemen olduğu bir dünyada sosyo-politik olarak bastırılan kadın sanat, hukuk, politika ve ekonomi gibi alanlarda kendini özgürce gösterememiş, temsil ve ifade edememiştir. Beard (2017), farklı dönemlerdeki kadınlar arasındaki sürekliliği araştırarak kadının tarih içerisinde erkekler tarafından nasıl sessizleştirildiğini ve güçsüz bırakıldığını incelemiştir. Erkek egemenliğini gösteren mitolojik bir örnekte şöyle bahsedilmektedir: Odysseus ve Penelope'un oğlu Telemachus, annesi Penelope'u halk önünde azarlayarak annesine, halk önünde konuşmanın erkeklere özgü olduğunu söyleyerek annesinin yukarıya eve çıkmasını söyler (Beard, 2017). Beard (2017), Homeros'un, aslında sadece mitolojik bir unsur olarak değil, yaşadığı dönemdeki erkek otoritesinin bir portresini çizdiğini, Antik Yunan ve Roma'dan günümüze kadar kadınların erkek egemenliğinin hâkim olması nedeniyle kitle önünde kendilerini ifade etmelerine izin verilmediğini ve kadının tarihte farklı biçimlerde sessiz bırakıldığını belirtmektedir. Dolayısıyla, sözlü kültürden yeni medya kültürüne kadar olan süreçte kadına atfedilen niteliklerin ve rollerin kadının sosyal bilinçdışında yer aldığı ve benzer temsillerle kendini gösterdiği söylenebilir. Ong (2013) sözlü ve yazılı kültürlerin farklı bilişsel temellere dayandığını belirtmektedir. Sözlü kültürde, söylenenleri bir defada hafizada tutmak ve bunun için hatırlanabilir benzetmeler, sıfat ve zarflar aracılığı ile yaşananların hafızada yer alması gerekmektedir (Ong, 2013). Bu anlamda sözlü kültürde, dilin birinci önceliği olan işitme işlevsel bir role sahiptir. Sözlü kültürde söylenenler geçicidir ve günümüze kadar tekrarlar, ritüeller, temsiller, kodlar, gelenekler ve seremonilerle devam etmektedir. Sözlü kültürde ön plana çıkan figürlerle ilgili genelde sözlü efsaneler yaratılmakta ve bu efsaneler tekrarlar aracılığı ile günümüze kadar ulaşmaktadır. 
Thomas (1992), Eski Yunan’da yazının önemli olduğunu, ancak sözlü kültüre göre her zaman ikincil olduğunu ifade etmektedir. Metinler her zaman sesli okunur ve o dönemde yazılan eserler genelde diyalog ya da sözlü kültürün özelliklerini yansıtacak şekilde oluşturulmuştur. Thomas (1992) sözlü ve yazılı kültürün radikal bir şekilde ayrı olduğunu düşünmemektedir. Aksine Antik Yunan' da daha az yazı ve daha fazla sözlü kültür aracılığı ile yoğun bir entelektüel dönem yaşandığını belirtmektedir. Dolayısıyla, 'sözlü kültürün karmaşık entelektüel faaliyetini engellemediğini' ve 'yazılı sözcüklerin, daha çok konuşmanın hizmetinde olduğunu' ifade etmektedir (Thomas, 1992: 4). Bu anlamda yazının sözlü kültüre hizmet etmekte olduğunu belirtmektedir. Sözlü kültür konusunda, Ruth (1977) genel bir sözlü kültürün olmadığını ve sözlü kültür içinde ayrımların olduğunu ifade etmektedir. Ruth (1977), sözlü kültürü, sözlü iletişim, sözlü kompozisyon ve sözlü iletim olarak üçe ayırmaktadır. Ruth’un (1977) bu ayrımları yapmasının nedeni, sözlü kültüre romantik ve nostaljik bir bakışının hakim olmasıdır. Dolayısıyla sözlü kültür, naif, basit, doğal, saf, bozulmamış, soylu vahşiliği, sadece halkı temsil eden, ideal, modern dünyanın karşısında ve ötesinde olan yaklaşımlardır (Thomas, 1992: 6-7). Thomas (1992), benzer şekilde bir efsane olarak sözlü kültürlerin ilkel, doğaya yakın, değişimin az olduğu, hafıza dışında kanıtların olmadığı, statik bir kültüre sahip olduklarının düşünüldüğünü ifade etmektedir. Oysa Thomas (1986) ve Thomas (1992) sözlü kültürler ile modern yazılı kültürler arasında bir sürekliliğin olduğunu düşünmektedir. Nitelik, nicelik ve değer bakımından ikilikçi düşünceden ziyade tarihsel sürekliliğe ve heterojenliğe vurgu yapılmaktadır (Beard, 2017; Ranković, 2010; Thomas, 1986; Thomas, 1992). Thomas (1992), Antik Yunan'da kadınların kamusal yaşamda hiçbir rolü olmadığını ve okuma-yazma bilmediğini belirtmektedir. Thomas (1992: 12), ‘Homeros’un yazılı eserlerinin büyük oranda sözlü kültüre dayandığını' ve her açıdan sözlü kültüre hitap eden bir topluma yazıldığını ifade etmektedir. Thomas'a göre, yazı, sözlü kültürü desteklemek için vardı. Thomas (1992), yazılı kültürden söz ederken aslında geç modern döneme kadar insanların çoğunun tüm uygarlıklarda yazmaktan ziyade okumayı tercih ettiğini, yazılanı sesli okumanın öncelikli ve yazmanın sadece belli bir zümrenin egemenliği altında olduğunu belirtmektedir. Böyle bir toplumda kadınların ikinci planda, eşitsiz ve erkeklere oranla değer bakımından daha aşağıda olduğu görülmektedir. Güzelliği ile ön plana çıkan Helen yüzünden 
Truva savaşının çıktığı ve mitolojide ilk yaratılan kadın Pandora ile Antik Yunan'da Altın Çağ'ın bittiği ve yasaklanan kutunun Pandora tarafından açılarak kötülüğün tüm dünyaya yayılmasına neden olduğu bilinmektedir (Demiralp, 2010).

Mitolojik kadın figürlerinde güzellik, uyumsuzluk, aşk, bakirelik ve doğurganlık gibi belli özelliklerin ön plana çıktığı görülmüştür. Afrodit, aşk, güzellik, zevk, tutku ve doğurganlığın simgeleri olarak temsil edilmiştir. Ayrıca, Afrodit tapınağı zevk tapınağı olarak da adlandırılmış ve genelde çekici, çıplak ve dikkat çeken olarak sembolleştirilmiştir. Benzer şekilde, Zeus'un kızı olan Helen ise güzelliği temsil etmiş ve güzelliği Truva savaşına neden olmuştur. Bu açıdan mitolojide kadın savaşın, uyumsuzluğun ve güzelliğin sembolleri olarak temsil edilmiştir. Tarihsel bir figür olan Kleopatra ise benzer şekilde güzellik, aşk, güç, tutku ve hırs olarak sembolize edilmiştir. Leonardo Da Vinci tarafından 16. yüzyılda bir portre olarak resmedilen Mona Lisa ise mutluluğu, gizemli gülümsemeyi ve çekici bakışı ile temsil edilmiştir. Meryem ise bakireliği ile ön plana çıkartılmıştır. Meryem figürüne benzer şekilde Antik Yunan mitolojisinde Artemis de bakireliği ile resmedilmiştir. Athena, Hera, Demeter ve Semele de güzellik, tutku ve zekilikleriyle mitolojide ifade edilmiştir. Güzellik, çekicilik ve güç gibi temel unsurlar mitolojik, sanatsal, tarihsel ve dini kadın figürleri arasında önemli ölçüde ön plana çıkmıştır. Beard (2017) Batı'da bu tür örneklerin mitolojide, sözlü kültürde ve tarihsel süreçte oldukça fazla olduğunu ve tüm özelliklerin ortaya çıkarılmasında kadının sessiz bırakılmasının tarihini yazmak istediğini belirtmiştir. Beard'a göre kadın, kendi varlığını ifade etmek için konuşturulmamış ve mümkün olduğunca sessizleştirilmiştir.

Kadınların temsili, ister mitolojik ister tarihsel olsun bu efsanelere dayanmaktadır. 15.yüzyılda matbaanın bulunmasıyla birlikte Ong (2013) radikal anlamda yeni bir bilinç şeklinin oluştuğunu ifade etmekte ve bu keşfi icat olarak nitelemektedir. Yazılı kültür, geleneksel medya içerisinde yer almakta ve tek yönlü bir iletişimi içermektedir. Bu tür kültürlerde ise kadının ön plana çıkması büyük oranda geleneksel medyayı elinde tutan iktidarların iradelerine bağlıdır ve bundan dolayı televizyon, gazete ve diğer bazı yazılı ve görsel medya türlerinin iktidara göre şekillendiği görülmektedir. Özellikle 
demokrasinin, hatta doğrudan demokrasinin gelişmediği ülkelerde kadınların özgürce söyleyebilecekleri kısıtlıdır. Geleneksel medyada kadının mağdur ve güçsüz olarak gösterildiği, geleneksel kadın rollerinin pekiştirildiği ve yeni medya ile başka bir yöne evrildiği gözlenmektedir. Zamanı ve mekânı aşan yeni medya ile birlikte karşılıklı etkileşim ön plana çıkmakta ve kadınlar için yeni özgürlük alanı açılmaktadır. Fakat bu özgürlük alanının ve bireyselliğin en üst seviyede yaşandığı yeni medyada kadınlar sosyo-politik olarak yeniden sorunsallaştırılabilmektedir. Kadınlar, geniş bir kamusal alan işlevi gören yeni medyada, medya özgürlüğü, çoğulculuğu, bağımsızlığı ve güvenliği çerçevesinde görünürlüklerini, bireysel bilgi ve veri paylaşımlarını büyük bir zaman ve emek harcayarak gerçekleştirmektedir (Dufy ve Hund, 2019; Tierney, 2013). Eleştirel tarih ve Foucault'cu (1972) anlamda arkeolojik anlayış içerisinde kadınlarla ilgili söylemlerin yeterince analiz edilmemesi yeni medya ile birlikte kadınların sosyo-politik açıdan yeniden kuramsallaştırılmasını gerektirmektedir. Erkeklerin kadınlarla ilgili baskıcı, ötekileştirici ve hegemonik söylemlerinin normalleştirilmesi, doğru olarak kabul edilmesi ve bu söylemlerin kadınların bedenlerini, zihinlerini ve yaşam alanlarını disipline etmesi kadınların sosyo-politik olarak güç kazanamamasına neden olmuştur. Bu problem, sözlü kültüryeni medya sürekliliğinde temel bir konu alanı olarak gerekli ilgiyi görmemiştir. Yeni medya içinde kadınların görünürlükleri, bilinirlikleri ve özgürlük alanları genişlemesine rağmen, kadınların gündelik yaşamda geri plana itilmesi, sessizleştirilmesi, sosyo-politik konularda konuşturulmaması, ekonomi ile ilişkilerinin kesilmesi ve toplum içindeki kadını güçlendirecek alanlara (politika, ekonomi, hukuk, akademi gibi) girilmesine izin verilmemesi arkeolojik bir yöntemle erkeklerin normalleştirici söylemlerinin yapısöküme uğratılmasını gerektirmektedir. Foucault'nun 'Doğruyu Söylemek' adlı yapıt1, bu tür bir arkeolojik araştırmanın nasıl yapılacağı ve söylemin nasıl yapısöküme uğratılacağının en önemli çalışmaları arasında gösterilebilir.

Tarih boyunca sosyo-politik alanın dışında bırakılan kadının özellikle İkinci Dünya Savaşı sonrası popüler kültürün bir nesnesi haline getirilmesi, bu kültürün sınırları içerisinde yaşamasının dayatılması ve bu yaşam pratiklerinin pekiştirilmesi önemli bir tartışma konusudur. Kitle ve tüketim kültürü olan popüler kültür, sosyo-politik konuların tartışılmasını engellemekte ve kadının da erkek egemen 
söylemleri tarafından sosyo-politik alandan uzaklaştırılıp popüler kültür içerisine dahil edilmesine neden olmaktadır. Postyapısalcılık, popüler kültürün söylemlerini yapısöküme uğratarak yeni anlam ve anlama olanakları açabilir. Yeni medyada ise popüler kültürü temsil eden kadın ile yine yeni medya aracılığı ile popüler kültüre direnen ve kadın sorunlarını gündeme getiren kadın çelişkili bir görünüm sunmaktadır. Yeni medyada kadın bu çelişkiler içerisinde farkındalık kazanarak sosyo-politik alana geçiş yapabilir.

\subsection{Popüler Kültür, Postyapısalcılık ve Kadın}

Sözlü kültürden itibaren kadının kendi sesini duyurmaya başlaması, tarihte çok geç ortaya çıkmıştır. Kadınların özellikle erkeklerle eşit olması gerektiği, boşanma hakkını elde edebilmesi ve siyasette yer alabileceği gibi konular 19.yüzyılın sonlarından itibaren Batı'da tartışılmaya başlanmıştır (Taş, 2016). Fransız devrimi, Endüstri devrimi ve kentleşme ile birlikte kadınlar kendi hakları konusunda taleplerde bulunmaya başlamış ve sosyal yaşamda hukuki haklar elde etmiştir. Özellikle, İkinci Dünya Savaşı'ndan itibaren yeni feminist akımlar, kadını farklı boyutlarda ele alarak hem kuramsal hem de pratik olarak kadın temsillerini çalışmışır (Josephine, 2001). Fakat kadının sosyal, ekonomik, hukuki, politik hakları tarihsel olarak dünya genelinde ve gelişmiş ülkeler olarak görülen Batı'da da tam anlamıyla sağlanamamış ve yeterli çalışmalar yapılamamıştır (Lin, 2019). Kadınların sosyo-politik, ekonomik, tarihsel ve hukuki olarak temsillerinin çalışılması yeterli olgunluğa henüz ulaşmamıştır. 1980'den itibaren İngiltere ve Amerika öncülügünde ortaya çıkan neoliberal ekonomi temelli politikalar, popüler kültür, popülist söylemler, tüketim toplumu, kültür endüstrisi ve küreselleşme içerisinde kadınların içinde bulundukları durum yeterli açıklanamamıştır (Archer, 2019; Lin, 2019). Kadınların tarihsel olarak sorunları kendileri ve feminist araştırmacılar tarafından detaylı ve eleştirel bakışla tartışılmadan yeni medya ile tanışmaları yeni bir problemi de gündeme getirmiştir (Archer, 2019). Sosyo-politik olarak kadının geri planda bırakılıp sosyo-politik olmayan konularla yeni medyada gündeme gelmesi yeni bir tartışma alanı açmıştır. Dolayısıyla, kadın popüler kültür kavramları, konuları ve yaşam tarzları ile gündeme gelmiştir. Kadın, kapitalizm ile yakından ilişkili olan popüler kültürün hedeflediği kitle kültürünün bir parçası haline gelmiştir. 
Storey (2010), popüler kültürün kitle kültürünü yarattığını ve kapitalizm ile doğrudan ilişkili olduğunu belirterek dijitalleşme ve yeni medya ile birlikte aslında dünyanın popüler kültür anlamında yekpare bir yapı haline getirilmeye çalışıldığını ifade etmektedir. Williams (1983: 237) popüler kültürü, 'kitleler tarafından beğenilme, ürünlerin değer ve tür bakımından aşağıda olma, kitlenin beğenisini kazanmak için bilinçli manipülasyon ve belli bir grup tarafindan büyük bir kitle için oluşturulmuş kültür olarak’ tanımlamaktadır. Storey (2010), popüler kültürü, alt kültür denilen kitle için yaratılmış ticari bir kültür olarak tanımlamaktadır. Storey, alt kültürün tersine, yüksek kültürün, bireysel sanat yaratımına, ahlaki ve estetik değere gönderme yaptığını ifade etmektedir. Storey (2010) ve Williams (1983), toplu üretim, toplu tüketim, kitle iletişim araçları ve ticari kültürün, popüler kültürün oluşmasında çok etkili olduğunu vurgulamaktadır. Storey (2010) ayrıca popüler kültür ile Yeni-Gramsci hegemonya kavramı arasında bir ilişki kurarak popüler kültürün aynı zamanda politik bir unsur olduğunu düşünmektedir. $\mathrm{Bu}$ düşünceye göre kitleler popüler kültürün bir parçası olmak için ikna edilmekte ve bu katılıma rıza göstermektedir (Gramsci, 1991; Storey, 2010). Kitle halinde tüketen ya da tüketmeye itilen insanlar, kapitalist elitlerin belirlediği değerlere, ideallere, amaçlara, kültürel ve politik anlamlara dâhil olarak yüksek bir uzlaşımla rıza davranışı göstermekte ve böylece üst kültür denilen ekonomik-politik elitlerin hegemonyasına girmektedir (Storey, 2010:80). Fakat, Fiske (1989), insanların, popüler kültür içinde pasif olmadığını ve elitlerle devamlı çatışma içinde olduğunu belirtmektedir. Dolayısıyla, Storey (2010) için de popüler kültür, şirketleşmiş dünya ile bu dünyaya karşı direnenlerin mücadele alanıdır. Storey’e göre, hegemoni pasif olarak doğrudan ve hiçbir çatışma olmadan oluşmamaktadır. Aksine, hegemoni, popüler kültüre direnç gösteren ile popüler kültüre dahil edilmenin bir çatışması olarak ortaya çıkmaktadır. Fakat söz konusu ekonomik elitin çıkarı olunca direnç, farklı araçlar (polis, ordu, hapishane, okul, devlet, darbe vb.) kullanılarak bastırılmaktadır (Althusser, 1971; Gramsci, 1991; Storey, 2010).

Popüler kültürün kuramsallaştırılması için diğer bir kavram da kültür endüstrisidir. Popüler kültür, temelde kapitalizm kültürüne hizmet eden bir endüstri olduğu için kültür endüstrisi kavramı ile ilişkili olduğu düşünülmektedir (Adorno, 1941; Storey, 2010). Adorno (2001) popüler kültürün sadece 
kapitalist elitlere hizmet ettiğini ifade etmektedir. Kapitalizm ile popüler kültür ilişkisine vurgu yapan Herman ve Chomsky (2010) ise, popüler kültürde yer alan büyük şirket elitlerinin çıkarına oluşturulan söylemin bir propaganda mekanizması olduğundan söz etmektedir. Storey (2010), popüler kültürü anlamada kültür endüstrisinin iki temel özelliği olan homojenliğe ve tahmin edilebilirliğe vurgu yapmaktadır. Marcuse (1968), popüler kültür içinde bireylerin öznelliğinin potansiyelinden söz etmekte ve otantik kültüre vurgu yaparak otantik olmayan popüler kültür karşısında her zaman bir direnç olabileceğini belirtmektedir. Marcuse (1968: 63), kültür endüstrisinin hedefinin, metalaştırma ve ticarileştirme işleviyle 'otantik kültürün eleştirel işlevini azaltmak' ya da yok etmek olduğunu ifade etmektedir. Fakat Adorno'nun direnç gösterme düşüncesini savunarak, Marcuse (1968), kültür endüstrisinin yarattığı homojenlik, tek tipleştirme, ve kalıplaştırmaya karşı olarak otantik kültürün direnebileceğini vurgulamaktadır. Ayrıca, Adorno (2001), popüler kültürün kalıplaşmış tüketim ifadelerine ve otomasyondan geçmiş ürünlere sürekli vurgu yaptığı için entelektüel bir düşünmenin engellendiğini ifade etmektedir. Adorno (2001) kültür endüstrisinin ve Storey (2010) de popüler kültürün geçici olduğunu, kapitalist elitlere hizmet ettiğini, homojen ve standart bir tüketim kültürü yarattığını belirtmektedir. Adorno (2001) ve Marcuse (1968) kültür endüstrisi bağlamında popüler kültürün alt kültürü oluşturduğunu, otantik olmayan bir kültüre gönderme yaptığını, eleştirelliği azalttığını ve entelektüelliğin ortaya çıkmasını engellediğini vurgulayarak direnmenin metalaştırılmayan ve ticarileştirilmeyen otantik kültür ile mümkün olabileceğini belirtmektedir. Popüler kültür içerisinde otantik bir kültürün olmadığına dair diğer bir kavram da Baudrillard tarafindan geliştirilen simulakra kavramıdır.

Baudrillard (2010), popüler kültür içerisinde simulakra kavramının orijinali olmayan bir kopyaya gönderme yaptığını belirtmekte ve buna hipergerçeklik de demektedir. Kopyalar gerçekliğin kopyası olmadığı için gerçeklik bulunmamaktadır. Baudrillard (2010), yeni kitle iletişim araçları ile aslında gerçeğin iletilmediğini ve gerçeğin zaten bize gösterilen şey olduğunu ifade ederek, anlam yokluğunun önemini vurgulamaktadır. Gerçek, artık simulakra (orijinali olmayan kopyalar) ve simülasyona (gerçek dünyanın taklidine) dönüşmüştür. Baudrillard'a (2010) göre gerçek gizleniyor değil, aksine hiçbir şeyin 
olmadığını gizleyen bir gerçeklik vardır. Kopya kitleler için hipergerçeklik olarak durmaktadır. Baudrillard (2010), popüler kültür içerisinde medya aracıllğ̆ ile en gerçekçi olayların bile hipergerçeklik haline getirildiğini ve sosyo-politik konuların gerçekliklerini yitirdiğini belirtmektedir. Baudrillard (2010), eğer görünüşün arkasında, ötesinde ve altında bir gerçeklik yoksa temsilin de olamayacağından söz etmektedir. Baudrillard (1998), popüler kültürde yer alan bireylerin aynı doğal dil gibi benzer kodlarla, sistemle, anlamla ve kurallarla iş gördüğüne vurgu yaparak bireylerin toplumsal olarak koşullandırıldığını ifade etmektedir. Bu koşullandırmanın sonucu olarak bireyler homojen hale getirilerek tüketmeleri konusunda eğitilmektedir (Baudrillard, 1998). Bu homojenlik, tek tipleştirme, kalıplaştırma, gerçekliğin anlamını yitirmesi ve kitle kültürünün oluşması yeni medya ile birlikte güçlü ve hızlı bir şekilde pekiştirilmektedir. Popüler kültür, kapitalizm içerisinde kendi devamlılığını sağlamak için mücadele ederken kuramsal anlamda bu kültürün iktidar ilişkilerini yapısöküme uğratan postyapısalcılık, kadınlar konusunda özcü, ikilikçi olmayan, üst anlatı içermeyen, sosyal diyaloga dayanan ve iktidar kurabilen söylem düzenin farkında olan bir düşünce sistemi geliştirmiştir.

Postyapısalcılık, yapısalcılığın kültür içindeki ikilikçi ilişkilere, sabit yapılara, aklın önceliğine ve modernitenin üst anlatılarına eleştirel bir bakış geliştirerek söylem düzenine, bilginin iktidarına, iktidar ilişkilerine, öznenin kültürel ve sosyal inşasına odaklanarak söylemi ve bilgiyi belirleyenlerin kimler ve hangi kurumlar olduğunu araştırmıştır (Butler, 1990; Falzon, 1998; Foucault, 1972, 1980; Jørgensen ve Phillips, 2002; Laclau ve Mouffe, 1985; Newman, 2001). Postyapısalcı düşünürler totolojik, mutlakçılık, evrensellik, özcülük ve ikilikçi sistemi, söylemi ve iddiaları barındıran tüm yapılara karşı çıkmışlardır. Laclau ve Mouffe (1985) için, genel, bütünlüklü ve tamamlanmış bir toplum imkânsızdır ve yoktur. Laclau ve Mouffe (1985) bu ifadeleriyle nesnel bir gerçeklik olarak toplumun var olamayacağını vurgulamaktadır. Onlara göre, bizler fiziksel ve sosyal dünyaya her zaman belli bir bakış açısı ve belli bir söylem ile girmekteyiz. Anlamın olanakları bu anlamda hiçbir zaman tüketilmemekte ve sosyal olarak inşa edilmektedir. Butler (1990), feminist akımda yapısalcı söylem düzenini eleştirerek performatif bir cinsiyet söylemini konu edinmektedir. Laclau ve Mouffe (1985) için, insanlar bulundukları toplumu ve toplumun kategorilerini sorgulamadan kabul etmiş ve Butler'ın ifadesiyle bunu 
her gün performe etmişlerdir. Bu anlamda, postyapısalcılara göre söylem ve anlam her zaman geçici, parçalı, belirsizdir ve genel bir ontolojik gerçekliği yansıtmamaktadır (Bauman, 2003; Butler, 1990; Falzon, 1998; Laclau ve Mouffe, 1985). Genel bir toplum ifadesi, Laclau ve Mouffe için boş bir gösterendir ve gerçekliğin bozulmuş bir hali olarak efsanevi bir tarzda yer almaktadır. Postyapısalcı feminizm, postyapısalcı kuram çerçevesinde ilerleyerek öznenin ne bir temeli ne de bir sonuç olduğunu vurgulamaktadır. Aksine, postyapısalcı feminizm bilinmeyene doğru açık ve yeniden anlamlandırmada yer alan sürece bağlı bir özneye vurgu yapmaktadır (Butler, 1992). Bu çalışma, kadın fenomenlerin kendi sosyo-politik öznelliklerini ve popüler kültürdeki temsillerini kendi hesaplarında ne ölçüde gerçekleştirebildiklerini sorgulamaktadır. Yeni medya ile birlikte kadının görünürlüğünün alanları, sınırları ve temsilleri araştırılmaktadır. Butlercı anlamda kadının öznelliğinin olanakları sorunsallaştırılmaktadır. Butler (1992), kadın ve erkek ikiliğini aşarak öznelerin ve öznelliklerin olanaklarını araştırmaktadır. Artık genelleştirici kadın-erkek söylemi yerine, kültürü, sınıfı, dinsel tercihi, politik seçimi, cinsel yönelimi, etnik grubu, iktidara direnebilen, öznelliğinin potansiyelinin farkında olabilen, sözlü kültürün olanaklarını gösterebilen, göçmen olması gibi olanaklar çerçevesinde yorumlanan kadınlara gönderme yapılmaktadır. Kadın, postyapısalcı kuram çerçevesinde çoğulculuğa, farklılığa, eylemliliğe önem veren, henüz belirlenmemiş olan, henüz bilinmeyen kategorilere, söylemlere, anlamlara açık olan, direnebilen, karşı çıkabilen, kendini ifade edebilen, kendisine dayatılan özcü değerlere ve ikilikçi düşüncelere karşı farklı söylemler üretebilen, iktidar ilişkilerinde stratejik ve taktiksel davranabilen, kendini sadece erkekler üzerinden ve erkekler karşısında tanımlamayan bir özne olarak yorumlanmaktadır (Butler, 2004; Fraser ve Nicholson, 1988; Irigaray, 1985; Scott, 1988). Bu çalışmada kadın fenomenlerin özcü ve ikilikçi değerlere karşı söylemler üretebilip üretemediği tartışılmıştır. Ayrıca kadınının sık görünür olmasının yetmeyip görünürlügünün içeriği ve bu içeriğin temsilleri de tartı̧̧ma konusu yapılmıştır. 1980 sonrası bu çalışmalar akademik dünyada göreceli olarak artmasına rağmen sosyal pratikte istenilen farkındalığı yaratmadığı düşünülmektedir (Dayan, 2019). Aksine yoksulluk, eğitim ve ücret eşitsizliğinin yanı sıra hala erkekler tarafından kadına yüklenilen eş olma ve çocuk büyütme sorumlulukları birçok ülkede sorun olarak güncelliğini korumaktadır 
(Littlejohn, 2019). Erkek egemen kültür ve baskıcı söylemler, kadınların sosyal ve politik yaşam alanlarında görülmemesine, bilinmemesine ve güç kazanamamasına neden olmuştur (Sancar, 2013). Fakat teknolojik gelişimlerle birlikte kadınların görünürlüğü ve tanınırlığı artmaya başlamış ve son yıllarda teknolojik gelişmelerin sonucunda ortaya çıkan yeni medya kadınlar için yeni bir kamusal alan yaratmıştır (Tierney, 2013).

\subsection{Yeni Medya Sürecinde Kadın}

Kapitalist elitler yeni medya ile birlikte daha fazla güçlenmesine rağmen, yeni medya ve popüler kültür endüstrisi, kadınların görünürlüğü ve paylaşımları açısından bir olanaklar dizisi de yaratmıştır. Bu çelişkili durum oldukça anlaşılabilir görünmektedir. Kadının, yeni medya öncesi dönemde görünürlüğünün az olması ve kapitalizm ile popüler kültürün baskın olması yeni medya ile birlikte kadının görünürlüğünü, bilinirliğini, paylaşımlarını ve aynı zamanda kapitalizmin de benzer şekilde etkisini arttırmaktadır.

Web 1.0 1990'ların başından 2000'li yılların ilk yılları kapsamaktadır. Web 1.0 uygulamasının interaktif özelliği minimum düzeyde olduğu için bu çalışmada sosyal medya Web 2.0 kategorisi içinde değerlendirilmektedir (Eccleston ve Griseri, 2008). Web 1.0 kullanıcı ve sabit bir temele dayandığ için interaktif anlamda kadının görünürlüğünün daha az olduğu bir dönemdir. Oysa Web 2.0 teknolojisi, sosyal ağ profillerinin tamamen interaktif ve katılımcı bir trendi temsil etmesi olarak tanımlanabilir (Eccleston ve Griseri, 2008). Dolayısıyla, yeni medya çerçevesinde sosyal medya da tamamen Web 2.0 teknolojisine dayanmaktadır. Sosyal medya, sanal topluluklar ve ağlarla bilgilerin, fikirlerin, duyguların ve farklı ifade biçimlerinin paylaşılarak interaktif bir şekilde dijital teknolojilerinin kullanılması olarak tanımlanabilir (Kietzmann vd., 2011; Leonardi vd., 2013). Sosyal medyanın ilk tarihi 1971'e dayandırılmakla birlikte 2004'te Facebook'un kullanıma girmesi kadınların görünümlerini belirgin kılmıştır. 2010'da instagramın kullanıma başlanması ile yeni bir alan ortaya çıkmıştır. Instagram fenomenleri olarak adlandırılan bu alan kadınların görünürlüğünü arttırmıştır. Freberg ve arkadaşları (2011) yeni medya fenomenlerini, takipçileri ile etkileşime geçerek onların tutumlarını, fikirlerini ve 
davranışlarını blog, tweet, instagram, facebook gibi araçlarla şekillendiren bağımsız gruplar olarak tanımlamışlardır. Fenomenler ayrıca yüksek statüde olan bireyler ya da güçlü sosyal etkisi olan kişiler olarak da ifade edilmektedir. Fenomenlerin temel hedefleri arasında piyasa ve marka mantığına göre hareket etmek ve takipçilerini etkileyip onları tüketime, beğenmeye ya da paylaşıma motive etmek yer almaktadır (Bronner \& Hoog, 2014). Her anını ve her etkinliği paylaşabilen kadın fenomenlerin sosyolojisi de son birkaç yılda çalış1lmaya başlanmıştır (Akikol, 2018; Akyazı, 2019; Aslan \& Ünlü, 2016; Özbaş \& Özkan, 2010; Sezgin, 2016; Solmaz \& Görkemli, 2012). Yeni medya ile birlikte ortaya çıkan kadınların paylaşımları, söylemleri ve pratikleri genelde dördüncü dalga feminizm ile ilişkilendirilmiştir.

Dördüncü dalga feminist akım, yeni medyada görünür olan kadınlar ile ilgilenmektedir (Chamberlain, 2017; Maclaran, 2015; Munro, 2013; Rivers, 2017).Yeni medya ile birlikte kadınlar daha önce deneyimlenmemiş bir şekilde biraraya gelerek herhangi bir haksızlığa karşı birarada durabilmekte ve toplanabilmektedir. Dördüncü dalga feminizminin amaçları kadınların yaşadıkları sorunları görünür kılmak, seslerini duyurmak, haklarını aramak, eyleme geçmek ve toplumda bir dönüşüm yaratmaktır (Alikılıç \& Baş, 2019; Avcı, 2017; Birol \& Bakır,2006; Sezgin, 2016). Yeni medya sosyal, ekonomik, politik ve hukuki olarak yaşanan olumsuzlukları paylaşarak bir eylem platformu haline gelmiştir. Kadınlar, sosyal ve sivil haklar konusunda yeni medyada bilinç kazanabilmektedir. Ayrıca yoğun olarak kadına karşı şiddet, saldırı, taciz, iş yerinde psikolojik şiddet, baskı, üniversitelerde cinsel taciz gibi konularda çok ön plana çıarak kadınların adalet arayışı yeni medya ile güçlenmiş̧tir (Crossley, 2015). Fakat tüm yeni medyada yer alan kadın fenomenlerin bu bilinçte olduğu anlamına gelmemektedir.

Beer (2013), Popüler Kültür ve Yeni Medya eserinde, popüler kültürün daha fazla ve güçlü bir şekilde ön plana çıkmasını sağlayan ivmenin yeni medya olduğunu belirtmektedir. Beer (2013), popüler kültürün küreselleşmesinde ve hızlanmasında yeni medya biyoteknolojik ekonominin rol aldığını düşünmektedir. Yeni medya, dijital bilgisayar ve ağ teknolojisi ile kültürel nesnelere, paradigmalara gönderme yapan ve hareketli algoritma temelinde anlık olarak değişebilen ve yazılımı sabit olmayan bir 
dijital platform ve kategori olarak tanımlanabilir (Manovich, 2003). Manovich (2001), yeni medya endüstrisine vurgu yaparak küreselleşme ile birlikte popüler kültürün de küresel bir homojenlik kazandığından söz etmektedir. Logan (2010), yeni medyayı çok kolay işlenebilen, depolanabilen, dönüştürülebilen, bilgileri hızlı bir şekilde getirebilen, hiper bağ kurulabilen, belki de en önemlisi ve en radikali kolay bir şekilde araştırma yapılabilen ve araştırma için en hızlı arama yapılabilen bir alan olarak tanımlamıştır. Yeni medya, ayrıca bireylerin kendini yazıll, görsel, sinematografik ve işitsel biçimlerde ifade edebileceği çoklu alan olarak betimlenmektedir (Dijk, 2006; Flew, 2008; Logan 2010; Törenli, 2005; Yanık, 2016). Yeni medya ifadesi bazı araştırmacılar için popüler kültürde olduğu gibi geçiciliği ifade etmektedir. Yeni kelimesinin aslında gerçek anlamda bir yeni olmadığını fakat geçiciliği ve ideolojiyi vurguladığı belirtilmektedir. Yeni kelimesi geçici olarak bir ütopyayı ve gerçek olmayanı kitlelere popüler kültür şeklinde dayatmaktadır (Dewdney \& Ride, 2006; Manovich, 2001; Yanık, 2016). Instagram gibi sosyal medya platformlarında üretilen, şekillendirilen, gösterilen ve resmedilenler bu bakış açısından hiper gerçekliği oluşturmakta ve aslında radikal bir anlam boşluğunu yaratmaktadır. Görsel, işitsel ve yazılı iletişim simülasyonu sürekli olarak akış sağlamakta, fakat anlam iletmemektedir. Dolayısıyla, yeni medya endüstrisi ile popüler kültür endüstrisi arasında bir süreklilik söz konusudur ve her ikisi de iktidar ile kapitalist elitlere hizmet etmektedir.

Yeni medya feminizmi çok karmaşık bir süreçtir ve beraberinde riskleri de getirmektedir. Çünkü dördüncü dalga feminizm teknolojiye ulaşamayan kadınlar ile ulaşan kadınlar arasında yaratılan sınıf farklılığını tartışmaktadır (Odine, 2013). Dolayısıyla kadınların dijital okuryazarlık ve yetişkin eğitimi gibi programlarla desteklenerek dördüncü dalga feminizm akımında yer almaları sağlanabilmektedir. Sosyal adaletsizliğin ve eşitsizliğin olduğu yerlerde kadınların bu alana dahil edilmesi oldukça zor görünmektedir. Yeni medya feminizminde diğer bir sorun ise, eylemlerin sadece internet aktivizmi ile sınırlı kalmasıdır. Ayrıca, ünlü kadınlar sosyal medyada ayrıcalıklı konumdadır, çünkü kendi seslerinin daha geniş bir kitlede yayılma imkanına sahiptir, ancak ünlü olmayan kadınlar için durum tam tersidir. Dezavantajlı konumda bulunan kadınlar, ünlü kadınlar kadar ayrıcalığa sahip olmayabilmektedir. Dolayısıyla, bir sosyal medya eşitsizliği ve adaletsizliği ile karşı karşıya kalınarak her zamankinden 
daha fazla bir sınıf farklılı̆ğ kendini gösterebilmektedir (Mitchell, 2016). Sosyal medyanın tüketim kültürü ve popüler kültür ile ilişkili olması kadınların konumunu olumsuz etkileyebilmektedir. Sosyal medyanın bu açıdan aporetik (çıkmaz) olarak ortaya çıktı̆̆ı ve sadece bazıları için özgürlük ve eşitlik getirdiği düşünülebilmektedir. Yeni medya feminizminde odaklanılması gereken diğer bir konu ise, sosyo-politik olarak etik bir sorunla karşı karşıya kalınmasıdır (Mitchell, 2016). Sosyal medyanın tüketim ve popüler kültür ile iç içe olması kadınların paylaşımlarının ve görünürlüklerinin de etik açıdan sorgulanması anlamına gelmektedir. Görünürlük ve paylaşım, neoliberal politikalara, tüketim ve popüler kültüre de hizmet ederek kadınların nesneleşmesi ve etik değerlerden uzaklaşması anlamına da gelebilmektedir. Etik değer bu çalışmada evrensel insan haklarına ve sosyo-politik konulara duyarlı olmayı içermektedir (Demir, 2017; Goodman \& Barnes, 2011). Yeni medya feminizminde söz edilen sosyal medya sadece eşitsizlik, adaletsizlik, yoksulluk, şiddet ve taciz konularına değinmemektedir. Yeni medya, aynı zamanda kadınlar için bir karşı hegemonya oluşturabilme, erkek egemen söylemleri yapı söküme uğratabilme, kolektif eyleme çağrıda bulunabilme, eleştirel farkındalık kazandırabilme ve direnç gösterebilme olanaklarını sağlamaktadır.

\section{AMAÇ VE YÖNTEM}

$\mathrm{Bu}$ çalışma sözlü kültürde temsil edilen kadınlar ile yeni medyanın en önemli uygulamalarından biri olan instagramda yer alan kadın fenomenlerin benzerlikleri ve farklılıklarını ortaya koymayı hedeflemektedir. 21. yüzyılda yeni medyanın yaygınlaşması ile sözlü kültürden bir kopuş meydana geldiği görülmektedir. Her şeyin görsel ve yazılı olması sözlü kültürün özelliklerini unutturabilmektedir. $\mathrm{Bu}$ çalışma sözlü kültür ile yeni medya arasında bir sürecin devam ettiğini ve sürekliliği olduğunu vurgulamayı hedeflemektedir. Ayrıca yeni medya sosyo-politik açıdan etik bir sorunu gündeme getirdiği için etik sorunların tartışılması da bu çalışmanın amaçları arasında yer almaktadır. Dolayısıyla, yeni medyanın özgürlük alanı sosyo-politik olarak incelenmektedir. Bu çalışmada, toplumsal dönüşüm için kadına yüklenen ve kadının kendisine yüklediği temsillerin eleştirel bir şekilde yeniden yorumlanması ve bu yorumlama yapılırken tarihsel sürekliliğin vurgulanması gerekliliği ele alınmaktadır. 
Çalışma nitel bir desende planlanmış olup görsel ve yazılı verileri tümevarımsal içerik analizi ile tematik olarak sınıflandırmıştır. Tümevarımsal içerik analizi, kuramsal çerçevede önceden hazırlanmış bir analize dayanmamaktadır. Aksine, tümevarımsal içerik analizi keşfedici bir analize dayanmaktadır (Özdemir, 2010). Ayrıca, açık kodlama, kategori yaratma ve soyutlama bu analizin temel özellikleri arasındadır (Neuendorf, 2002). Elde edilen veriler arasında karşılaştırma yapılarak ve gözlemler sınıflandırılarak bilginin üretimi sağlanmaktadır. Analizler nicel çalışmalarda olduğu gibi lineer bir tarzda ilerlememektedir. Aksine, kodlama süreci uzun olduğu ve veriler defalarca gözden geçirildiği için, daha az standart, daha karmaşık ve daha zor bir analiz türüdür (Neuendorf, 2002; Patton, 1990). Tümevarımsal içerik analizi nomotetik özellikte olmayıp genelde idyografiktir. Bu açıdan genelleştirici bir paradigma yerine yorumlayıcı bir yaklaşımı benimsemektedir. Kodlamaların ve kategorilerin yorumlanması ile birlikte mutlak ve genel olmayan bir bilgiye ulaşılmaktadır. Tümevarımsal içerik analizi ile çalışma yapan araştırmacılar, araştırılan konular ve veriler arasında bir ortak yön, şema ve örüntü olduklarını düşünmekte ve kodlama çalışmalarını bu çerçevede analiz etmektedir (Potter \& Levine-Donnerstein, 1999). Bu tür analizler belirlenmiş görsel ve yazılı sistematik olarak incelenmektedir (Topkaya, 2006). Bu çalışmada kodlama çalışmaları sosyoloji alanında uzman iki öğretim üyesi ile yapılmıştır. Kronbach alfa güvenilirlik analizi sonucu ise 0.79 olarak elde edilmiştir.

Çalışma sözlü kültürde yer alan on kadın figürü ve 2019 yılında instagramda fenomen olan on kadını dahil etmiştir. Veriler sosyal medya analizi ve ölçümleme raporlama analiz (boomsocial.com) web sitesinden elde edilmiştir. Sosyal medya fenomenliği sürekli değiştiği için 2019 y1lının belli bir döneminde en çok takip edilen kadınların listesi yapılmıştır. Sosyal bilim araştırmalarında bireylerin isminin verilmesi etik olmadığı için sadece takipçi sayısı ve özelliklerinin verilmesi etik bir durum olarak değerlendirilmiştir. Sosyal medya fenomeni, belli aralıklarla gönderilerini paylaşan, belli bir konuda uzmanlığı olan ve bu uzmanlık bilgisini istekli ve gönüllü takipçileriyle paylaşıp ün kazanmış kimse olarak tanımlanabilir (Enke ve Borchers, 2019). Kadınlar seçilirken popüler olma ve görsel temsilleri göz önünde bulundurulmuştur. 
Tablo 1. Fenomen Profillerinin Betimsel İstatistiği

\begin{tabular}{|c|l|c|l|c|c|}
\hline Katılımcılar & Mesleği & Yaş & Ĕğitimi & Medeni durumu & Çocuk sayısı \\
\hline K1 & Doktor & 42 & Kadın doğum uzmanı & Bekâr & 0 \\
\hline K2 & Akademisyen & 39 & Çocuk gelişimi ve eğitimi & Evli & 1 \\
\hline K3 & Mesleği yok & 21 & Psikoloji & Bekar & 0 \\
\hline K4 & Modacı & 42 & Moda Tasarımı & Evli & 0 \\
\hline K5 & Model & 35 & Lise mezunu & Bekâr & 0 \\
\hline K6 & Estetisyen & 39 & Turizm & Evli & 1 \\
\hline K7 & İş kadını & 38 & Girişimcilik & Evli & 2 \\
\hline K8 & Oyuncu & 33 & Müzikal ve Tiyatro & Evli & 2 \\
\hline K9 & İş kadını & 26 & Ekonomi & Bekar & 0 \\
\hline K10 & Modacı & 29 & Moda pazarlama yöneticiliği & Evli & 2 \\
\hline
\end{tabular}

Kadın fenomenlerin yaş, meslekleri, medeni durumları ve çocuk sayılarına bakıldığında kadın fenomenlerinden sekizi, 20 - 40 yaş arasındadır; iki fenomen kadın ise 40 yaş üzerindedir. Fenomenlerden sadece bir kadının mesleğini yapmadığ 1 ve bir kadının da lise mezunu olduğu, altı kadının evli, beş kadının çocuğunun olduğu, dört kadının da bekar olduğu görülmektedir. Katılımcılar eğitimlerini tıp, çocuk gelişimi, psikoloji, moda tasarımı, turizm, girişimcilik, tiyatro, ekonomi ve moda pazarlama olmak üzere farklı alanlarda tamamlamışlardır. Bir kadın fenomen tedavi gördüğü için aldığı eğitimin mesleğini yapamadığı, ancak yine de yaşamaya dair büyük umutlarının olduğu yönünde söylemlerini takipçileri ile paylaşarak vurgulamaktadır.

Verilerin toplanmasında görsel ve yazılı araçlar seçilmiştir. Öncelikle tarihte popüler olan kadınlar taranmıştır ve yaygın olarak toplumda bilinen ve kabul edilen kadınlar çalışmaya dahil edilmiştir. Tarihte ünlü olan kadınların seçiminde resim bölümü uzmanlarından yardım alınmıştır. Instagramda yer alan kadın fenomenler ise takip edilme sayılarına göre belirlenmiştir. Görseller seçildikten sonra temalar belirlenmiştir ve bu temaların özellikleri benzerlik ve farklılık ölçütlerine göre sınıflandırılmıştır. 
Tablo 2. Paylaşımların Betimsel İstatistiği

\begin{tabular}{|c|c|c|c|}
\hline Katılımcılar & Takipçi & Takip & Gönderi \\
\hline K1 & 603b & 243 & 3534 \\
\hline K2 & $931 b$ & 341 & 4320 \\
\hline K3 & $1,2 \mathrm{~m}$ & 199 & 404 \\
\hline K4 & $701 \mathrm{~b}$ & 1233 & 1277 \\
\hline K5 & $642 \mathrm{~b}$ & 1781 & 3009 \\
\hline K6 & $454 \mathrm{~b}$ & 934 & 4990 \\
\hline K7 & $434 \mathrm{~b}$ & 741 & 482 \\
\hline K8 & $1,9 \mathrm{~m}$ & 1543 & 2777 \\
\hline K9 & $87,2 \mathrm{~b}$ & 838 & 414 \\
\hline K10 & $1,8 \mathrm{~m}$ & 539 & 5742 \\
\hline
\end{tabular}

Kadın fenomenlerin Tablo 2'deki betimsel istatistiklerine bakıldığında, üç kadın fenomenin takipçi sayısının çok yüksek oranda olduğu (takipçi aralığı 1,2m ile 1,9m) görülmektedir ve diğer yedi kadın fenomenlerin takipçi sayıları ise 87,2b ile $931 \mathrm{~b}$ arasındadır. Takip ettikleri kişi sayısı aralığı 199 ile 1781 kişi arasındadır. Yayınladıkları gönderi/fotoğraf sayısı ise, 404 ile 5742 arasındadır. Genelde fenomenlerin takip ettiği kişi sayısının daha az olduğu görülmektedir. Ayrıca gönderinin miktarı ile takipçi sayısı arasında doğrusal bir korelasyon olmadığı görülmektedir. Dolayısıyla, içerik analizi ile gönderilerin niteliği ve yazılanların temaları sınıflandırılmıştır.

\section{BULGULAR}

Çalışmanın genel olarak bulgularına bakıldığında hem sözlü hem de yeni medyada erkek egemen söylemlerinden dolayı kadınların sosyo-politik alanlarda yer almasının yasaklandığı, daha çok geçicilik, bedensellik ve popülerlik gibi konularla ön plana çıkarıldıkları görülmektedir. Sözlü kültürde kadınlar politikalar içerisinde entrika düzenleyen ya da güzellikleri ile ön plana çıkarılırken, yeni medyada yer alan kadınlar da benzer şekilde güzellik ve bulundukları mekânın estetiği gibi konularla tanınmışlardır. Hem sözlü hem de yeni medyada erkek egemen baskıdan dolayı kadının aslında toplumu değiştirmede etkin bir rol alamadığı gözlenmiş̧ir. Dolayısıyla, kadınların sözlü kültürde temsil edilişlerine bakıldığında erkekler tarafından sosyo-politik alanların dışına itildiği ve kadınların yeni medyadaki paylaşımlarında da risk içermeyen konuları seçtikleri görülmüştür. Kadınların sosyo-politik konularda 
paylaşımlarının ya da temsillerinin yeni medyada olmaması toplumda dönüşümün ve değişimin yeterli düzeyde olmadığını göstermiştir.

Tablo 3. Fenomenlerin Paylaşım Temaları

\begin{tabular}{|c|c|c|c|c|c|c|c|c|c|c|}
\hline Boyutlar & K1 & K2 & K3 & K4 & K5 & K6 & K7 & K8 & K9 & K10 \\
\hline İdeoloji & Atatürkçü & - & - & - & - & - & - & - & - & - \\
\hline Doğa & Yürüyüş & $\begin{array}{l}\text { Yürüyüş } \\
\text { Park }\end{array}$ & $\begin{array}{l}\text { Park } \\
\text { Kafe }\end{array}$ & Yürüyüş & Yürüyüş & Yürüyüş & $\begin{array}{l}\text { Çiftlik } \\
\text { Yürüyüş }\end{array}$ & Tatil & Spor & Park \\
\hline Hayvan & Köpek & - & Köpek & $\begin{array}{l}\text { Kedi } \\
\text { Köpek }\end{array}$ & Köpek & Köpek & Köpek & $\begin{array}{l}\text { Kedi } \\
\text { Köpek }\end{array}$ & Köpek & - \\
\hline Seyahat & Yurtdıs1 & Yurtiçi & - & Yurtdıș1 & Yurtdıș1 & Yurtdıș1 & Yurtdıș1 & Yurtiçi & Yurtdıș1 & Yurtdıș1 \\
\hline $\begin{array}{l}\text { Özel } \\
\text { yaşam }\end{array}$ & $\begin{array}{l}\text { İş } \\
\text { arkadaşları }\end{array}$ & $\begin{array}{l}\text { Aile } \\
\text { Çocuk }\end{array}$ & Aile & Eşi & Arkadaş & $\begin{array}{l}\text { Eşi } \\
\text { Çocuk }\end{array}$ & Aile & $\begin{array}{l}\text { Aile } \\
\text { Çocuk }\end{array}$ & Arkadaş & $\begin{array}{l}\text { Aile } \\
\text { Çocuk }\end{array}$ \\
\hline
\end{tabular}

Fenomen kadınların paylaştığı temalar Tablo 3'te gösterilmiştir. Paylaşımlarda sadece bir kadın ideolojik görüşünü net olarak göstermiştir. İdeoloji boyutu dışında doğa, hayvan, seyahat ve özel yaşam boyutları paylaşımlardaki konuların sıklık derecelerine bakarak ortaya çıkarılmıştır. Doğa boyutunda yürüyüş ve yeşil temasının ağırlıklı olduğu; hayvan boyutunda fenomenlerin tercihlerinin çoğunlukla köpek olduğu; seyahat boyutunda yurt dışına daha çok seyahat etmeyi tercih ettikleri; özel yaşamlarında ise, aile ve arkadaşları ile daha çok paylaşım yaptıkları gözlenmiştir. Ortaya çıkan boyutlarda fenomenlerin paylaşımlarında benzer konu (yemek, sağlik, güzellik gibi) ve mekân tercihi (kafe, spor salonu gibi) temel paylaşımlarını oluşturmaktadır. Fenomenler paylaşımlarını fotoğrafın dışında video ya da canlı çekim yaparak da çeşitlendirmektedir. Fenomenler özellikle özel yaşamları ile ne kadar çok görsel paylaşırlarsa, daha çok insana ulaşmak ve samimi görünme hedefinde olabilmektedir. Hatta fenomenler özel yaşamlarından görselleri daha çok tasarımlayarak anında paylaşmakta ve doğum günleri, aile yemekleri, ev dekorasyonu, makyaj, alışveriş anlarını takipçilerine göstermektedir. 
Tablo 4. Fenomenler İle İlgili Sosyal Projeler Boyutu

\begin{tabular}{|c|l|}
\hline Katılımeılar & Projeler \\
\hline K1 & Her Yönüyle Kadın Sağlığı \\
\hline K3 & Aile ve eğitmenlere yönelik pratik çalışmalar \\
\hline K4 & Kanserle mücadele \\
\hline K5 & Kaplumbağaları kurtarma gönüllüsü değerse dünya değişir \\
\hline K6 & Doğal görünme hakkında bilgilendirme \\
\hline K7 & Diyabet ve beslenme hakkında bilgilendirme \\
\hline K8 & Sosyal projesi bulunmamaktadır \\
\hline K9 & Akciğer kanserine karşı farkındalık \\
\hline K10 & Sosyal projesi bulunmamaktadır \\
\hline & \\
\hline
\end{tabular}

Fenomenlerin sosyal sorumluluk projeleri kategorisi, Tablo 4'te gösterilmektedir. İki kadın fenomenin bir projede yer aldığı görülmezken, sekiz kadının aktif ve çok istekli olarak projelere katıldığı görülmüştür. Bu projelerin konusu kadın sağlığı, eğitim, kanser tedavisi, hayvanları koruma, kadının gücü, doğallık ve beslenmedir. Özellikle farkındalık oluşturmak için yaptıkları çalışmaları takipçilerine göstermek istemişlerdir. Bundan dolayı bilinçlenme ve bilgilendirme üzerine yaptıkları çalışmaları fotoğraf, kısa hikaye oluşturma, video gibi görseller kullanarak paylaşım yaptıkları görülmektedir. 
Tablo 5. Tarihte Ünlü Kadın Figürler ve Özellikleri

\begin{tabular}{|c|c|c|c|c|c|}
\hline Kadınlar & Güzellik-Aşk & $\begin{array}{c}\text { Sifatlar- } \\
\text { Betimlemeler }\end{array}$ & Estetik/Gösterilen(sembol) & Aile-Çocuk & Yaşadığı Yer \\
\hline Afrodit & $\begin{array}{l}\text { Aşk, Güzellik } \\
\text { Tanrıçası }\end{array}$ & $\begin{array}{l}\text { İşveli, cilveli, gönül } \\
\text { alıcı, çıplak }\end{array}$ & $\begin{array}{l}\text { Çekicilik } \\
\text { Genç kadın }\end{array}$ & $\begin{array}{l}\text { Evli, yasak } \\
\text { ilişki } \\
15 \text { çocuk }\end{array}$ & Olimpos ve Kıbris \\
\hline Truvalı Helen & Kraliçe & $\begin{array}{l}\text { Güzellik, altın sarısı } \\
\text { saç } \\
\text { Zümrüt yeşili göz }\end{array}$ & $\begin{array}{l}\text { Moda } \\
\text { Dünyanın en güzeli }\end{array}$ & $\begin{array}{l}\text { Evli } \\
1 \text { çocuk }\end{array}$ & $\begin{array}{l}\text { Truva Sparta } \\
\text { Mutlular adası }\end{array}$ \\
\hline VII.Kleopatra & $\begin{array}{l}\text { Tanrıça } \\
\text { Kraliçe }\end{array}$ & $\begin{array}{l}\text { Zeki } \\
\text { Politik }\end{array}$ & $\begin{array}{l}\text { Çekicilik } \\
\text { Hırslı,etkili }\end{array}$ & $\begin{array}{l}\text { Evli } \\
4 \text { çocuk }\end{array}$ & $\begin{array}{l}\text { Antik Misır } \\
\text { İskenderiye }\end{array}$ \\
\hline Mona Lisa & Gizemli gülümseme & $\begin{array}{l}\text { Belirsiz } \\
\text { Anitsal }\end{array}$ & Leonardo da Vinci portresi & $\begin{array}{l}\text { Evli } \\
2 \text { çocuk }\end{array}$ & $\begin{array}{l}\text { İtalya/Floransa } \\
\text { Louvre müzesi }\end{array}$ \\
\hline Meryem & $\begin{array}{l}\text { Bakire } \\
\text { İsa'nın annesi }\end{array}$ & $\begin{array}{l}\text { Önemli } \\
\text { Kutsal kişi }\end{array}$ & $\begin{array}{l}\text { Meryem Ana } \\
\text { Bakire Meryem }\end{array}$ & 1 çocuk & $\begin{array}{l}\text { Beytüllahim/İsrail } \\
\text { Efes/Selçuk }\end{array}$ \\
\hline Artemis & $\begin{array}{l}\text { Bakire } \\
\text { Güzellik }\end{array}$ & $\begin{array}{l}\text { Koruyucu, iffetli } \\
\text { Sarı saçlı }\end{array}$ & $\begin{array}{l}\text { Ay,Avc1, vahşi } \\
\text { Ebedi bakire }\end{array}$ & Evlenmemiş & $\begin{array}{l}\text { KüçükAsya (günümüz } \\
\text { Türkiye) }\end{array}$ \\
\hline Athena & $\begin{array}{l}\text { Barış,Işık,Sanat Kır } \\
\text { Tanrıçası }\end{array}$ & $\begin{array}{l}\text { Baş koruyucu } \\
\text { Zeki, stratejik }\end{array}$ & $\begin{array}{l}\text { Kalkan, mızrak } \\
\text { Zeytin dalı,genç }\end{array}$ & Evlenmemiş & $\begin{array}{l}\text { Olimpos dağı } \\
\text { Atina Truva }\end{array}$ \\
\hline Hera & Evlilik Kraliçesi & $\begin{array}{l}\text { Güçlü, cesur } \\
\text { Koruyucu, gür } \\
\text { saçli, güzel }\end{array}$ & $\begin{array}{l}\text { Tavuskuşu } \\
\text { Nar,başörtülü,olgun }\end{array}$ & $\begin{array}{l}\text { Evli } \\
6 \text { çocuk }\end{array}$ & Olimpos dağ \\
\hline Demeter & $\begin{array}{l}\text { Toprak, Tarım } \\
\text { Tanrıçası }\end{array}$ & $\begin{array}{l}\text { Bakire } \\
\text { Güzel örgülü saç }\end{array}$ & $\begin{array}{l}\text { Buğday } \\
\text { Ekin }\end{array}$ & Evlenmemiş & $\begin{array}{l}\text { Olimpos dağı } \\
\text { Girit, Trakya }\end{array}$ \\
\hline Semele & $\begin{array}{l}\text { Ahiret, Toprak } \\
\text { Tanrıçası }\end{array}$ & $\begin{array}{l}\text { Güzellik, tutkulu } \\
\text { Sıcak bakışlı, hayat } \\
\text { dolu }\end{array}$ & Ölümlü & $\begin{array}{l}\text { Evli değil } \\
1 \text { çocuk }\end{array}$ & Olimpos dağ1 \\
\hline
\end{tabular}

Tarihte ünlü kadın figürlerin özellikleri Tablo 5'te verilmiştir. Bu özelliklerin güzellik-aşk, sıfatbetimleme, estetik-gösterilen(sembol), aile-çocuk ve yaşadıkları yer olmak üzere detaylı boyutları ele alınmıştır. Güzellik ve aşk boyutunda aşk, toprak, doğurganlık, ahiret, evlilik, barış, bakirelik ve gizemliliği temsil eden tanrıça ve kraliçelik ünvanları ile kadınların ön plana çıktığı görülmektedir. Kraliçe ya da tanrıça olarak bilinen kadınlar dünyanın en güzel kadını, kadınları ve evlilikleri koruyan, işveli, zeki, belirsiz, politik, kutsal, stratejik, cesur, güçlü, sarı saçl1, hayat dolu gibi farklı betimlemelerle kendi dönemleri içinde ün kazanmışlardır. Tarihte bu ünlü kadınlar farklı sembollerle tanımlanmış ve işaret edilmişlerdir. Çekiciliği, ilk pantolon giymesi ile dikkat çekerek modayı işaret etmesi, bir portresinin yapılarak ün elde etmesi, kutsal kitapta adı doğrudan söylendiği için inanç sistemlerinde gösterilen, liderliği ve farklı sembolik nar, buğday, tavus kuşu, kalkan, mızrak, zeytin dalı gibi ürünlerle 
temsil edilmeleri, ayrıca genç, olgun, çekici, bakire, ölümlü kadın imgeleri ile kendi toplumlarında bilinmeleri bu kadınların yüksek statüye sahip güçlü kadınlar olduğuna işaret etmektedir. Kadın olmaları sebebiyle aile yaşamları ilgi çekici ve merak uyandırıcıdır. Bu kategoride ortaya çıkan özellikler evli, çocuklarının olması, yasak ilişki yaşanması, babasız bir çocuğa sahip olunması ile mucizevi, yüce, kutsal ve önemli bir kadın olunması, bazı kadınların ise hiç evlenmemiş ve çocuğunun olmamasıyla ün kazanması ilgi çekiciliği artıımıştır. Kadınların yaşadıkları yerler ya ta tapınakları ise, Kıbrıs adası, Truva, Sparta, İskenderiye, Louvre müzesi, Efes, Küçük Asya, ve Olimpos dağları olarak gösterilmiştir. Sözlü kültürde ün kazanmış bu kadınların güzellikleri, aşkları ve entrikaları ile ilgili çok fazla vurgu söz konusudur. Güzelliklerine ek olarak, yardımseverlikleri, koruyuculukları, savaşçı olma gibi özellikleri ile diğer kadınlardan ayırıcı özelliklere sahip olduklarına dikkat çekilmiştir.

\subsection{Kadınların Söylemleri ve Görselleri ile İlgili Bulgular}

Sözlü kültürdeki kadınlara baktığımızda yüz güzellikleri ön planda tutulmuştur. Meryem figürü genelde çocuğu ile resmedilmiştir. İsa çok önemli bir tarihsel figür olduğu için annesi ile resmedilmiş ve diğer figürlerin tersine daha muhafazakâr bir görünüm kazanmıştır. Sözlü kültürün içinde yer alan mitolojik ve tarihsel kadın temsillerine bakıldığında toplumda bir değişim yaratma bakımından ikinci planda kalmaktadır. Güzellik, doğurganlık, gülümseme, bakirelik, tutku, çekicilik ve hırs gibi temalar vurgulanmıştır. Kadınların sözlü kültürde sosyo-politik konular çerçevesinde temsil edilmediği görülmektedir. Geçicilik ve bir anlamda kadına yüklenen doğurganlık ve cinsellik rolleri çok baskın görünmektedir. Benzer bulgular yeni medyada da görülmektedir. Fakat yeni medya ile sözlü kültür arasındaki fark, sözlü kültürde kadın resmedilmekte, temsil edilmekte ve yazı ile belirlenmektedir. Fakat yeni medyada kadın, kendi kendini özgürce temsil etmektedir ve kendi görünürlüklerini paylaşırken sözlü kültürdeki kodlara yakın bir kodla kendini resmetmektedir. Her iki kültürde de kadının sosyopolitik konularda yer almadığı görülmektedir.

Kadın fenomenlerinin hepsinde öz çekim (selfie) bulunmaktadır. Topluma mesaj verme anlamında kadın fenomenlerden biri toplumu sağlık konusunda bilgilendirici görseller kullanmakta, video çekimi 
ve duyuru da yayımlamaktadır. Böylece yeni medya aracını bu anlamda toplum yararına kullanmaktadır. Sosyal faydaya ek olarak otobiyografik anlamda yaşantılarını yazılı olarak paylaşarak kendine bir söylem alanı yaratmaktadır. Gündelik yaşamda belli anlarda yaşadıklarını ise öz çekim ile bildirmektedir. Dezavantajlı gruplara yardım ederken lüks mekânlarda yaşadıklarını da görsel uzama yansıttığı görülmektedir. Araştırmacı açısından bu bir paradoks olarak görülebilmekte, çünkü dezavantajlı insanların asla ulaşamayacağı lüks mekânlarda yaşaması bir çelişki olarak yorumlanabilmektedir. Aynı zamanda, etkili sosyal projeleri ile toplumu bilgilendirme ve farkındalık çalışmaları da yürütülmektedir. Aynı katılımcı tüketim toplumu, sosyal sorumluluk ve belli bir toplumsal/ulusal ideolojiyi paylaşmasından dolayı eklektik bir model sunduğu şeklinde yorumlanabilmektedir.

Diğer bir kadın fenomen ise, daha çok kadınları takipçi sayısına eklemeyi hedeflemesi açısından önemli bir fenomen olarak yer almaktadır. Bu kadın fenomen ise çocuk ve annelik konusunda sosyal projelerini yeni medya üzerinden paylaşmaktadır. Pratik anlamda birçok aktiviteyi paylaşarak, medyada topluma bir rol model olarak gösterilmektedir. İyi bir işe sahip olması, eşini, çocuğunu ve aile birliğini önemsediğini görsel olarak paylaşması, insanlara toplumsal olarak güçlü bir kadın imajını vermektedir. Çocuğu ile yaptığı etkinlikleri profesyonel mesleki bilgisi ile sunması insanlar üzerinde özellikle kadınlarda güven duygusunu güçlendirme hedefinde olduğu düşündürmektedir. Profesyonel iş yaşamının getirdiği bilgi ve tecrübenin yanında, bir kadın, eş ve anne olması ile de toplumda kendine güvenen, ekonomik özgürlüğü olan, çalışkan ideal kadın görüntüsü sunabilmektedir. Başka bir kadın fenomen ise, bir hastalık konusunda yaşadıklarını otobiyografik anlamda paylaşarak toplumda bir farkındalık yaratmaya çalışmaktadır. Yaşadığı hastalığa rağmen yaşama dair pozitif olması ve bunu samimi olarak paylaşması, hasta olan insanların toplumda dezavantajlı olmadığını hayatlarına devam edebileceklerini gösterme çabası olarak yorumlanabilmektedir. Yaşam sevincini doğada yürüyüş yapma, farklı şehirleri seyahat etme gibi aktiviteler yaparak, hayvan sevgisini sürekli vurgulayarak ve insanlar arası iletişimini samimiyetle, özellikle de ailesi ile olan ilişkisini görsellerle paylaşarak güçlü durmaya çalışmaktadır. 
Kadın fenomenlerden üçü ise, daha çok moda kültürü ile ilgilenerek modayı ön plana çıkarmakta ve moda yanında hayvanları koruma, çocuklar, kadınlar ve annelik konusunda sosyal projeler ile de kendilerini göstermektedirler. Moda ile ilgili profesyonel tecrübelerini, iş deneyimlerini, aldıkları eğitimleri, moda haftalarında yaptıkları seyahatleri sıklıkla takipçileri ile paylaşmaktadırlar. Daha çok kadın takipçilere hitap eden paylaşımlarında sadece moda ile ilgili değil, aynı zamanda eş ve çocuklarına ayırdıkları zamanı nasıl değerlendirdikleri, estetik, güzellik, sağlıklı beslenme, diyet programları, yemek yedikleri restoranlar, alışveriş için kullandıkları markalar ile de farklılıklarını göstermeye çalışmaktadırlar.

Kadın fenomenlerden biri ise, güzellik, kozmetik çalışmaları ve paylaşımları ile ön plana çıkmaktadır. Estetikle ilgilenen kadın fenomen, turizm alanında aldığı eğitimi birleştirerek kendi işini kurmayı tercih etmiş ve bir marka olma yolunda ilerlemiştir. Yapmış olduğu paylaşımlar daha çok cilt bakımı, sağlığı ve doğal görünüm ile ilgilidir. Sade ve estetik yaşam biçimini önemsediğini özel yaşamından fotoğraf veya videolar paylaşarak vurgulamaya çalışmaktadır. Aşırı makyaj ya da parıltılı kıyafetlerden özellikle kaçındığını ve kadın olmanın bu abartılıkla ilgisi olmadığını kısmi olarak takipçilerine hissettirmektedir. Girişimcilik konusunda ise başka bir kadın fenomen kurduğu işteki başarısını, fotoğrafları ve videoları ile paylaşmaktadır. Girişimcilik konusundan farklı olarak kadın ve çocuk konusunda da farkındalık çalışmalarını yazılı olarak yeni medya uygulaması üzerinden paylaşmaktadır. Özellikle eşi, çocukları ve anneliği nasıl yaşadığı ile ilgili paylaşımlarını samimi olarak göstermeye çalışmaktadır. Ailesi ile seyahatte, tatilde geçirdiği zamanı çok sevdiğini, sosyal sorumluluk projelerine ve ayrıca işine ayırdığı zamanı kendi profilini oluşturan en önemli öğeler olarak göstermektedir. Başka bir kadın fenomen ise, mesleğinin yanında daha çok eşi, çocukları ve gündelik sosyal pratikleri ile ön plana çıkmaktadır. İşinin sanatla ilgili olmasından dolayı reklam, oyunculuk gibi yer aldığı projeleri takipçileri ile gün atlamadan paylaşmaktadır. Annelik ve babalığın ortak bir iş olduğunu, kadın ve erkek cinsiyet rollerinin de eşit olarak paylaşılabileceğini bir arada oldukları fotoğraf veya videoları ile bir yorum olarak göstermektedir. Başka bir kadın fenomen ise seyahat, sağlık, eğitim ve beslenme ile ilgili paylaşımlarda 
bulunmaktadır. Ayrıca ölümcül hastalıklar konusunda toplumda farkındalık çalışmalarını paylaşımlarında hassasiyetle önemsemektedir.

\section{TARTIŞMA}

Çalışmanın sonuçları sözlü kültürde kadınların temsil edilişlerinde ve yeni medya kültüründe kendilerini temsil etme biçimlerinde güzellik, doğurganlık ve bedene vurgu kategorilerinde benzerlik olduğunu göstermektedir. Antik Yunan'dan itibaren kadının politik arenada değişim yapabilecek derecede güç kazanması engellenmektedir. Bugün yeni medyada fenomen olan bazı kadınların politik alana vurgu yapmaması tarihsel çerçevede değerlendirilebilmektedir. Beard (2017) böyle bir durumun yaşanmasının muhtemel nedenlerinden birini kadının evde, sosyal ve politik yaşamdan uzaklaştırılarak sessiz bırakılması olarak görmektedir. Güzellik, çekicilik, seyahat, zekâ, moda ve sosyal sorumluluk gibi riskli olmayan konuların ön plana çıkarılarak seçildiği görülmektedir. Bu çalışmadaki kadın fenomenlerin genel olarak eşitsizliğe, adaletsizliğe, ayrımcılığa ve kadına şiddete karşı bildirimlerde bulunmadığ1 tespit edilmiştir. Kadının daha çok bedeni üzerinden görünürlüğünü ortaya koyduğu görülmektedir. Popüler ve tüketim kültürünün baskın olması, kadınların fenomen olmasını sağlayan temel unsurlar arasındadır (Akyazı, 2019; Aydoğan, 2009; Karaduman, 2017). Entelektüel, politik ve sosyal içerikli gönderilerin popüler kültürün baskın olduğu dönemde beğenilmeme kaygısından dolayı, kadınlar daha çok tüketim temelli gönderiler paylaşmaktadır (Hatipler, 2017). Ayrıca sağlık tüm bireyler için önemli olduğu için popüler konular arasında yer almaktadır. Tüm dünyanın küresel anlamda şirketleştiği düşünülecek olursa sosyo-politik konuların tartışılması fenomen olmaya yetmeyebilmektedir (Harvey, 2007). Beard'ın (2017) belirttiği gibi, Antik Yunan'dan itibaren Batı tarihinde kadının politik alanda görülmesine ve konuşmasına izin verilmemesi politik alanın onlar için riskli olduğu anlamına gelmektedir. Tarihsel olarak politik söylemlerin erkeğe bırakılması hegemonik bir güç olarak kadınlara etkisi olumsuz olmuştur. Marxist anlamda ekonomik ve Gramsci anlamda politik, sosyal ve hukuk alanlarında kadın erkekler tarafından güçsüz bırakılmıştır. Kadınların aslında yeni medya ile görünürlük kazanmasına rağmen, Marxist anlamda altyapıya (ekonomik) ve Gramsci'nin üstyapı (hukuk, politika) 
anlayışlarına değinmemeleri ve bu alanlarda büyük bir kitleye istikrarlı bir şekilde paylaşımda bulunmamaları düşündürücüdür ve bu sorunsalın tarihsel bir süreklilik içinde olduğu düşünülmektedir.

Neoliberal politikalar aracılığı ile düşünme yönteminin zihinlerde olması, popüler ve tüketim kültürünün kadınlar aracılığı ile pekiştiği ifade edilmektedir (Kaymas, 2006; Lalancette ve Raynauld, 2019). Politikacılar, özellikle erkekler, yeni medyayı politikanın etkili bir aracı olarak kullanabilmekte ve sosyo-politik konuları tartışabilmektedir (Lalancette ve Raynauld, 2019). Fakat politika dışında yer alan sivil halkın ve özellikle kadınların sosyo-politik konularda toplumda eleştiri yapması beklenmemektedir. En fazla takip edilen kadın fenomenlerin çoğunlukla özgür bir şekilde sosyo-politik konulara değinmediği görülmektedir. Kadınların kendilerini bu şekilde temsil etmeleri eleştirel sosyoloji açısından önemli bir sorundur, çünkü yeni medyadaki paylaşımlar risk içermeyen popüler konulardır. Bir anlamda yeni medya fenomenleri İkinci Dünya Savaşı sonrasında ortaya çıkan Hollywood temelli kültür endüstrisinin devamı niteliğindedir. Her ne kadar savaştan sonra feminist akımlar ve düşünceler sosyo-politik konulara odaklansa da 1980 sonrası Thatcherizm ile birlikte neoliberal politikalar sosyopolitik kazanımların önemini azaltmıştır (Harvey, 2007). Kültür endüstrisi ve popüler kültür ile hareket eden yeni ekonomik politikalar yeni medyada etkisini göstermektedir. Hatta öyle ki, 1960-1970 yıllarında politik ve ekonomik elitler kültür endüstrisinin merkezi olan Hollywood'da birçok yasaklar getirmiştir ve hatta bazı Hollywood şirketlerini devlet tamamen kontrolü altına almıştır. Sosyo-politik konuları gündeme getiren, kapitalizmi eleştiren, işçileri savunan filmler yasaklanmış, yönetmenler hapse atılmıştır. 1954 yapımlı Toprağın Tuzu filmi bir kadın hareketinin yükselişini ve kadınların haklarını elde edişini anlatmaktadır. Filmdeki oyuncular gerçek dünyadaki insanlardır ve hiçbiri aktör değildir (Lorrence, 1999). Çünkü politik ve ekonomik elitler kadın hareketleri ya da işçi hareketleri ile ilgili tüm şirketleri, aktörleri ve aktristlerin rol almasını yasaklamıştır ya da böyle bir filmde hiç kimse rol almak istememiştir (Lorrence, 1999). Kadınlar için tarihin böyle bir mücadeleden geçtiğine bakılacak olursa, kadının politik ya da sosyal alanda yer almaması yeni medya fenomenlerini de etkilediği düşüncesine götürmektedir. Telemachus'un annesi Penelope'a toplum önünde konuşmaya izin vermemesi ve evine gitmesini söylemesi çağdaş tarihte hala bir sorunsal olarak devam etmektedir (Beard, 2017). Yeni 
medyada kadınların görünürlüklerinin artması kadınların anlamlı bir şekilde sosyo-politik olarak özgür olduğu anlamına gelmemektedir. Kadınların, ekonomik ve politik alanı etkisi altına alan neoliberal politikaları eleştirerek yeni medyayı daha etkin kullanması önerilebilmektedir. Çünkü neoliberal politikaların hız kazanmasına en çok yardımcı olan unsur yeni medyanın ve herkesin her an ünlü olabilme potansiyelidir. Beğenilme arttıkça ticari kazancın artma eğilimi de artmaktadır (Cwynar-Horta, 2016). Kadınların sağlıktan bedensel güzelliğe kadar her şeyi kullanabilmesi neoliberal pragmatik bir tutum olarak yorumlanabilmektedir. Dolayısıyla kadının yeni medyada görünürlüğünün artması sosyopolitik hakların daha çok olduğu anlamına gelmemelidir. Feminist akımların sosyo-politik tartı̧̧malarının aksine kadın cinsiyeti bir araç ve nesne olarak performatif bir nitelik göstererek modern anlamda ikilikçi düşünceye hizmet etmektedir. Tüketim kültürü içinde kadın olmak neoliberal politikaları daha da küreselleştirmektedir. Sözlü kültürde sadece üst sınıfın sanat eserlerinin üst sınıf tarafından üretilmesi yoksulluk içinde yaşayanlara bir olanak sağlamamaktadır. Sözlü kültürde üst sınıfta yer alan kadın imgesel olarak kalmaktadır ve sosyal pratikleri görülmediği için sözlü kültür içinde efsaneleşmektedir. Yeni medyada kadınlar tüm görünürlükleriyle fenomen olurken sözlü kültürde sözel alan içinde (yer alan kadınlar) efsane olarak yaşamaktadır. Dolayısıyla, fenomenlik ve efsanelik tarihsel olarak örtüşmektedir, sadece nitelikleri farklıdır. Sosyolojik anlamda yeni medya kadınlarının sosyal pratikleri onların yeni medya sosyolojilerini oluşturmaktadır ve fenomenlikleri de popüler kültür içerisinde geçici olabilmekte, terk edilebilmekte ve unutulabilmektedir (Cwynar-Horta, 2016). Oysa kadınların sözlü kültürde efsane olarak yaşamaları edebi, sanatsal ve felsefi anlamda tarih boyu üretilmelerine olanak sağlamaktadır. Radikal sosyoloji bakımından her iki durum da etik açıdan sosyopolitik sorunların çözümüne hizmet etmemekte ve yoksulluğun hakim olduğu bir dünyada tüketim kültüründeki yoksulluk ile ilgili paylaşımlar inandırıcıllğını yitirmektedir ve takipçiler tarafından eleştirilmektedir. Dolayısıyla, etik bir sorun ortaya çıkmaktadır. Fenomen olan bir kadın etik bir sorun ortaya çıkınca günlerce tartışma konusu olabilmektedir. Bu durumun nedeni, popüler ve tüketim kültürü piyasa mantığına ve neoliberal politikalara dayanmasıdır. Piyasa mantığının etik olmamasından dolayı fenomen kadınlar, yeni medyada paylaşımları ile kendilerini zor duruma düşürebilmektedir. 
Uzun süre sosyo-politik konuları paylaşmayıp Türkiye'de sosyo-politik anlamda üzücü bir olayla ilgili kadın fenomenler yorum yaptıklarında çok eleştirildikleri ve kısa sürede gözden düştükleri görülmüştür. Çünkü paylaşımlarıyla söylemleri arasında etik sorunun olması takipçilerin dikkatini çekmektedir (Vardal, 2015). Yeni medya örtük ya da açık etik ilkeler çerçevesinde yürümektedir. Marx'ın yorumladığ1 ve eleştirdiği burjuva ve proletarya karşıtlığı bugün yeni medyada kendini göstermektedir. Yoksullar ile neoliberallerin mücadelesi arasına sıkışan ve daha çok neoliberal tüketim kültürünü seçen kadın fenomenlerin etik bir çıkmaz ile karşı karşıya olduğu düşünülmektedir. Sözlü kültürde bu tür bir etik sorun efsane şeklinde devam ederek edebiyatta ya da sanatta eleştirilebilmekte ve yapıbozuma uğratılabilmektedir. Oysa yeni medyada etik sorumluluk sosyolojik anlamda derin dikkati gerektiren bir konudur. Yeni medyada fenomen kadınların sadece temsillerinin betimlenmesi popüler kültürün ve neoliberal politikaların devam ettirilmesi anlamına gelmektedir. Eleştirel sosyoloji temelinde yeni medyada kadınların temsilleri tarihsel süreklilik içerisinde yeniden ele alınarak özcü bir yaklaşım benimsenmeden etik temelde sosyo-politik konulardan uzak durmanın ve neoliberal politikalara eleştiri yapılmamasının nedenleri sosyal diyalog çerçevesinde yorumlanmalıdır. 


\section{SONUÇ}

Bu çalışma, sözlü kültürde temsil edilen kadınların erkek egemen baskısının sonucu olarak politik alanın dışına itildiği ve kadının duygusal özellikler, aşk, güzellik, doğurganlık ve bakirelik gibi kodlarla temsil edildiğini göstermektedir. Yeni medya içerisinde yer alan bazı kadın fenomenlerin de sosyo-politik konularda paylaşımlarda bulunmadığı görülmektedir. Aksine, popüler kültürün yarattığı kitle kültürünün içinde konumlanarak sosyo-politik olmayan bildirimlerde bulunmaktadır. Yeni medyada kadın her ne kadar görünür olsa da, sözlü kültürde kadının kendini temsil etmesine yeterli olanağı sağlamayan erkek egemen toplum günümüzde de başka formlarda bu egemenliğini devam ettirerek kadının sosyo-politik alana girmesini engellemektedir.

Hem sözlü kültür hem de yazılı kültürdeki kadın temsillerinin cinsellik, geçicilik, güzellik, moda, popülerlik, aşk, gezi, seyahat, duygusallık, doğurganlık gibi sosyo-politik konuları içermeyen ortak özellikleri olduğu görülmektedir.

Yeni medyada kadınların sosyo-politik konuları paylaşmaması politik iktidarın aldığı pozisyon ya da erkek egemen toplumun kadından apolitik davranması beklentisinden kaynaklanabilmektedir. Dolayısıyla, yeni medya ile birlikte kadın sosyolojisi karmaşık tarihsel, sosyal, politik ve kültürel sürecin üretken bir konusu olarak güncelliğini korumaktadır. Bu süreçte önemli olan, tarihsel olarak bastırılan kadının yeni medya aracılığı ile bu söylemlere bir direnç geliştirerek tepkide bulunmasıdır.

Gelecekte yapılacak çalışmalarda üniversitede yaşam alanı bulan akademisyen, öğrenci, yönetici kadınların yanı sıra iş dünyası, ev yaşamı, kamusal alan gibi üniversite dışında yer alan kadınların bir araya gelerek sosyal medyada sosyal adalet, eşitlik arayışı, adil ücret dağılımı, eşit eğitim gibi sosyopolitik konular hakkında platformlar kurulabilir. Ayrıca, akademi dışında yer alan kadınların dünyası nesneleştirilmeden ve araştırma nesnesi olmadan risk alınarak sosyo-politik konularda dayanışma içerisinde bulunulabilir. Sosyo-politik konuların tartışılmadığı bir yeni medya, yeni dünya düzeninde kadınların apolitikleşmesini pekiştirmeye devam edecektir. Yeni medya ile yeni söylem alanı yaratılarak bir direnişin olduğu vurgulanabilir. Bu çalışma, tarih boyunca erkek egemenliğinden dolayı kendi 
temsillerini oluşturmaktan yoksun bırakılan ve sosyo-politik paylaşımlarda bulunmayan kadınların kendi tarihlerini yeniden yazmaları eleştirel düşünebilen bilinçli kadınlar ile mümkün olabileceğini göstermektedir. 


\section{SUMMARY}

This study aims to reveal the similarities and differences between women represented in oral culture and women's phenome na in Instagram, one of the most important applications of new media. With the spread of new media in the 21 st century, it is seen that there has been a break from oral culture. The fact that everything is visual and written can make you forget the features of oral culture. This study aims to emphasize that there is a continuum between the oral culture and new media. In addition, the discussion of ethical problems is also among the aims of this study, since the new media brings up an ethical problem in socio-political terms. Therefore, the freedom sphere of the new media is examined sociopolitically. This study deals with the critical reinterpretation of the representations imposed on women and on themselves for social transformation and the necessity of emphasizing historical continuity while interpreting this. When the findings of the study are examined in general, it is seen that women are prohibited from taking part in socio-political areas due to their male-dominated discourse in both verbal and new media, and they are mostly brought to the fore with issues such as transience, physicality and popularity. In oral culture, women who organize intrigue within politics or are brought to the forefront with their beauty, women in the new media are similarly known for issues such as beauty and the aesthetics of the place they are in. It has been observed that women cannot take an active role in changing the society due to male-dominated pressure in both verbal and new media. Therefore, when we look at the representation of women in oral culture, it is seen that men are pushed out of socio-political spheres and women choose risk-free issues in their posts in new media. The absence of women's sharing or representation on socio-political issues in the new media has shown that the transformation and change in society is not at the desired level. In future studies, academicians, students, and administrative women who find a living space at the university, as well as women outside the university, such as business, home life, and public space, come together and social media such as social justice, equality seeking, fair wage distribution, equal education. Platforms can be established on topics. In addition, solidarity on socio-political issues can be achieved by taking risks without objectifying the world of women outside the academy and without the object of research. A new media where socio-political issues are not 
discussed will continue to reinforce the apoliticization of women in the new world order. It can be emphasized that there is a possibility for resistance by creating a new discourse with the new media. This study shows that women who have been deprived of forming their own representations due to male domination throughout history and who do not share socio-political shares can rewrite their own history with conscious women who can think critically. 


\section{KAYNAKÇA}

Adorno, T. W. (1941). On Popular Music. Zeitschrift für Sozialforschung, 9(1), $17-48$.

Adorno, T. W. (2001). The Culture Industry: Selected Essays on Mass Culture. New York: Routledge.

Akikol, R. (2018). Kadın Dijital Göçmenlerin Facebook Kullanımı ve Mahremiyet Ilişkisi. Connectist: Istanbul University Journal of Communication Sciences, 54, 1-36.

Akyazı, A. (2019). Mahremiyetin Dönüşümü: Ünlülerin Instagram Paylaşımları Üzerine Bir Araştırma. Gaziantep University Journal of Social Sciences, 18(1), 197-216.

Alikılıç, Ö., Baş, Ş. (2019). Dijital Feminizm: Hashtag'in Cinsiyeti. Fe Dergi, 11(1), 89-111.

Althusser, L. (1971). Ideology and Ideological State Apparatuses. London: New Left Review.

Archer, C. (2019). Social Media Influencers, Post-Feminism and Neoliberalism: How Mum Bloggers' 'Playbour'is Reshaping Public Relations. Public Relations Inquiry, 8(2), 149-166.

Aslan, A., Ünlü, D. G. (2016). Instagram Fenomenleri ve Reklam İlişkisi: Instagram Fenomenlerinin Gözünden Bir Değerlendirme. Maltepe Üniversitesi İletişim Fakültesi Dergisi, 3(2), 41-65.

Avc1, A. (2017). Her Zaman Çevrimiçi Olmak. Epokhe Sosyal Bilimler Dergisi, 1(1), 1-24.

Aydoğan, F. (2009). Eleştirel Perspektiften Yeni Medya. Marmara İletişim Dergisi, 15, 185-194.

Baudrillard, J. (1998). The Consumer Cociety: Myths and Structures. London: Sage Publications.

Baudrillard, J. (2010). Simülakrlar ve Simülasyon. O. Adanır (Çev.). Ankara: Doğu Batı Yayınları.

Bauman, Z. (2003). Modernlik ve Müphemlik. İsmail Türkmen (Çev.). İstanbul: Ayrıntı Yayınları.

Beard, M. (2017). Women and Power: A Manifesto. London: Profile Books.

Beer, D. (2013). Popular Culture and New Media: The Politics of Circulation. New York: Springer.

Birol, M., Bakır, Z. N. (2006). Instagram Fenomenlerinin Paylaşımları Üzerinden Göstergebilimsel Bir İnceleme. The Journal of International Scientific Researches, 4(2), 195-221.

Bronner, F., de Hoog, R. (2014). Social Media and Consumer Choice. International Journal of Market Research, 56(1), 51-71.

Butler, J. (1990). Gender Trouble: Feminism and the Subversion of Identity. New York: Routledge. 
Butler, J. (1992). Contingent Foundations. J. Butler and Scott, J.W. (Ed.) Feminists Theorize the Political içinde (s. 3-21). NewYork: Routledge.

Butler, J. (2004). Undoing Gender. New York : Routledge

Chamberlain, P. (2017). The Feminist Fourth Wave: Affective Temporality. New York: Springer.

Crossley, A. D. (2015). Facebook Feminism: Social Media, Blogs, and New Technologies of Contemporary US Feminism. Mobilization: An International Quarterly, 20(2), 253-268.

Cwynar-Horta, J. (2016). The Commodification of the Body Positive Movement on Instagram. Stream: Culture/Politics/Technology, 8(2), 36-56.

Dayan, C. (2019). Konumlandırılmış Akademik Marjinalizasyondan Konumlandırılmış Biraradalığa: Toplumsal Cinsiyet ve Kadın Çalışmaları. Fe Dergi, 11(2), 51-64.

Demir, A. (2017). Panopticon ve Synopticon Geriliminde Özgürlük Paradoksu. Kaygı Uludăg Üniversitesi Fen-Edebiyat Fakültesi Felsefe Dergisi, 28, 55-65.

Demiralp, D. (2010). İlkçağ Anadolu Efsanelerinin En Güzeli: Troyalı Helena. Gazi Akademik Bakış, 7, 201-213.

Dewdney, A. ve Ride, P. (2006). The New Media Handbook. New York: Routledge

Dijk, V. J. (2006). The Network Society. London: Sage.

Duffy, B. E., Hund, E. (2019). Gendered Visibility on Social Media: Navigating Instagram's Authenticity Bind. International Journal of Communication, 13 (20), 4983-5002.

Eccleston, D., Griseri, L. (2008). How Does Web 2.0 Stretch Traditional Influencing Patterns? International Journal of Market Research, 50(5), 575-590.

Enke, N., Borchers, N. S. (2019). Social Media Influencers in Strategic Communication: A Conceptual Framework for Strategic Social Media Influencer Communication. International Journal of Strategic Communication, 13(4), 261-277.

Falzon, C. (1998). Foucault and Social Dialogue: Beyond Fragmentation. London: Routledge.

Fiske, J. (1989). Understanding Popular Culture. London: Unwin Hyman.

Flew, T. (2008). New Media: An Introduction. South Melbourne: Oxford University Press. 
Foucault, M. (1972). The Archaeology of Knowledge. London: Routledge.

Foucault, M. (1980). Truth and Power. C. Gordon (Ed.) Power/Knowledge, Selected Interviews and other Writings 1972-1977 içinde. Hemel Hempstead: Harvester Wheatsheaf.

Foucault, M. (2010). Doğruyu Söylemek. Kerem Eksen (Çev.). İstanbul: Ayrıntı Yayınları.

Fraser, N., Nicholson, L. (1988). Social Criticism without Philosophy: An Encounter between Feminism and Postmodernism. Theory, Culture \& Society, 5(2-3), 373-394.

Freberg, K., Graham, K., McGaughey, K., ve Freberg, L. A. (2011). Who are the Social Media Influencers? A Study of Public Perceptions of Personality. Public Relations Review, 37(1), 9092.

Goodman, M. K., Barnes, C. (2011). Star/Poverty Space: The Making of the 'Development Celebrity’. Celebrity Studies, 2(1), 69-85.

Gramsci, A. (1991). Selections from Prison Notebooks. London: Lawrence and Wishart.

Harvey, D. (2007). A Brief History of Neoliberalism. Oxford : Oxford University Press, USA.

Hatipler, M. (2017). Postmodernizm, Tüketim, Popüler Kültür ve Medya. Bilgi Sosyal Bilimler Dergisi, $1,32-50$.

Herman, E. S., Chomsky, N. (2010). Manufacturing Consent: The Political Economy of the Mass Media. New York: Random House.

Irigaray, L. (1985). This Sex which is not One. Ithaca, NY : Cornell University Press.

Jørgensen, M. W., Phillips, L. J. (2002). Discourse Aanalysis as Theory and Method. London: Sage Publications.

Josephine, D. (2001). Feminist Teori. A. Dora (Çev.). İstanbul: İletişim Yayınları.

Karaduman, N. (2017). Popüler Kültürün Oluşmasında ve Aktarılmasında Sosyal Medyanın Rolü. Erciyes Üniversitesi Sosyal Bilimler Enstitüsü Dergisi, 31(43), 113-133.

Kaymas, S. (2006). İletişim Politikalarında Paradigma Değişimi ve Yeni Medya: Medya ve İletişim Politikalarında Yöndeşme. Galatasaray Üniversitesi İletişim Dergisi, 5, 97-124. 
Kietzmann, J. H., Hermkens, K., McCarthy, I. P. ve Silvestre, B. S. (2011). Social Media? Get serious! Understanding the Functional Building Blocks of Social Media. Business Horizons, 54(3), 241251.

Laclau, E., Mouffe, C. (1985). Hegemony and Socialist Strategy. Towards a Radical Democratic Politics. London: Verso.

Lalancette, M., Raynauld, V. (2019). The Power of Political Image: Justin Trudeau, Instagram, and Celebrity Politics. American Behavioral Scientist, 63(7), 888-924.

Leonardi, P. M., Huysman, M. ve Steinfield, C. (2013). Enterprise Social Media: Definition, History, and Prospects for the Study of Social Technologies in Organizations. Journal of ComputerMediated Communication, 19(1), 1-19.

Lin, M. I. A. O. (2019). Educational Thoughts of Western Radical Feminism. Cross-Cultural Communication, 15(3), 21-25.

Littlejohn, K. (2019). Can the Subaltern Speak?: Challenges of Postcolonial Historiography. Teaching History, 53(4), 38-41.

Logan, R. K. (2010). Understanding New Media: Extending Marshall McLuhan. Frankfurt: Peter Lang.

Lorence, J. J. (1999). The Suppression of Salt of the Earth: How Hollywood, Big Labor, and Politicians Blacklisted A Movie in Cold War America. Albuquerque, NM: UNM Press.

Maclaran, P. (2015). Feminism's Fourth Wave: A Research Agenda for Marketing and Consumer Research. Journal of Marketing Management, 31 (15-16), 1732-1738.

Manovich, L. (2001). The Language of New Media. Cambridge: The MIT Press.

Manovich, L. (2003). New Media from Borges to HTML. The New Media Reader, 1(2), 13-25.

Marcuse, H. (1968/2007). One Dimensional Man. London: Penguin.

Mitchell, K. (2016). Celebrity Humanitarianism, Transnational Emotion and the Rise of Neoliberal Citizenship. Global Networks, 16(3), 288-306.

Munro, E. (2013). Feminism: A Fourth Wave? Political Insight, 4(2), 22-25.

Neundorf, K. (2002). The Content Analysis Guidebook. Sage Publications Inc., Thousand Oaks, CA.

Newman, S. (2001). From Bakunin to Lacan: Anti-Authoritarianism and the Dislocation of 
Power. Lanham, MD: Lexington Books.

Odine, M. (2013). Role of Social Media in the Empowerment of Arab Women. Global Media Journal, 12(22), 1-30.

Ong, W. J. (2013). Orality and Literacy. London: Routledge.

Özbaş, S., Özkan, S. (2010). Kadın Sağlığını Geliştirmede Medyanın Kullanımı ve Etkisi. TAF Preventive Medicine Bulletin, 9(5), 541-546.

Özdemir, M. (2010). Nitel Veri Analizi: Sosyal Bilimlerde Yöntembilim Sorunsalı Üzerine Bir Çalışma. Eskişehir Osmangazi Üniversitesi Sosyal Bilimler Dergisi, 11(1), 323-343.

Patton M. Q. (1990). Qualitative Evaluation and Research Methods. Newbury Park: Sage Publications.

Potter, W. J., Levine-Donnerstein, D. (1999). Rethinking Validity and Reliability in Content Analysis. Journal of Applied Communication Research, 27(3), 258-284.

Ranković, S. (2010). The Oral-Written Continuum as a Apace. S. Ranković, L. Melve ve E. Mundal (Ed.), Along the Oral-Written Continuum; Types of Texts, Relations and Their Implications içinde (s.37-68). Utrecht: Brepols Publishers.

Rivers, N. (2017). Postfeminism(s) and the Arrival of the Fourth Wave. New York: Palgrave Macmillan.

Ruth, F. (1977). Oral Poetry. Its Nature, Significance, and Social Context. Cambridge: Cambridge University Press.

Sancar, S. (2013). Türk Modernleşmesinin Cinsiyeti: Erkekler Devlet Kurar, Kadınlar Aile Kurar. İstanbul: İletişim Yayınları.

Scott, J. W. (1988). Deconstructing Equality-versus-Difference: Or, the Uses of Poststructuralist Theory for Feminism. Feminist Studies, 14(1), 33-50.

Sezgin, A. A. (2016). Türkiye'de Instagram Fenomenleri: Sosyal Paylaşım Ağlarında İnşa Edilen Yaşamların Kültürel Analizi. Journal of International Social Research, 9(43), 2144-2150.

Solmaz, B., Görkemli, H. N. (2012). Yeni Bir İletişim Alanı Olarak Sosyal Medya Kullanımı ve Konya Kadın Dernekleri Örneği. Selçuk Üniversitesi Sosyal Bilimler Enstitüsü Dergisi, (28), 183-189.

Storey, J. (2010). Cultural Studies and the Study of Popular Culture. Edinburgh: Edinburgh University Press. 
Taş, G. (2016). Feminizm Üzerine Genel Bir Değerlendirme: Kavramsal Analizi, Tarihsel Süreçleri ve Dönüşümleri. Akademik Hassasiyetler, 3(5), 163-175.

Tierney, T. (2013). The Public Space of Social Media: Connected Cultures of the Network Society. New York: Routledge.

Thomas, K. (1986). The Meaning of Literacy in Early Modern England. G. Baumann (Ed.), The Written Word: Literacy in Transition içinde (s. 97-131). Oxford: Clarenton.

Thomas, R. (1992). Literacy and Orality in Ancient Greece. Cambridge: Cambridge University Press.

Topkaya, E. (2006). Sosyal Bilimlerde Nitel Araştırma Yöntemleri. Eğitimde Kuram ve Uygulama, 2(2), 113-118.

Törenli, N. (2005). Yeni Medya, Yeni İletişim Ortamı. Ankara: Bilim ve Sanat.

Vardal, B. (2015). Yeni Medya ve Etik. International Multilingual Academic Journal, 2(1), 95-103.

Yanık, A. (2016). Yeni Medya Nedir Ne Değildir? Journal of International Social Research, 9(45), 898910. 